\title{
Chiral Resolution of Mandelic acid through Preferential Cocrystallization with Nefiracetam
}

Xavier Buola ${ }^{\mathrm{a}}$, Camila Caro Garrido ${ }^{\mathrm{a}}$, Koen Robeyns ${ }^{\mathrm{a}}$, Nikolay Tumanov ${ }^{\mathrm{b}}$, Laurent Collard ${ }^{\mathrm{a}}$, Johan Wouters ${ }^{\mathrm{b}}$ and Tom Leyssens ${ }^{\mathrm{a},}$ *

anstitute Of Condensed Matter and Nanosciences, UCLouvain, 1 Place Louis Pasteur, B-1348 Louvain-la-Neuve, Belgium

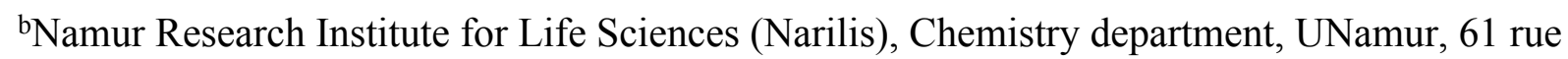
de Bruxelles, B-5000 Namur, Belgium 


\section{Contents}

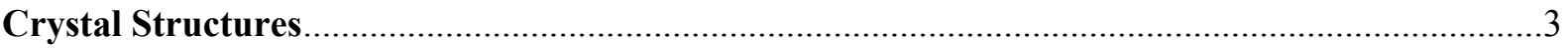

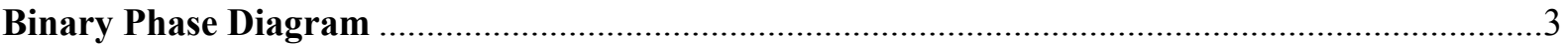

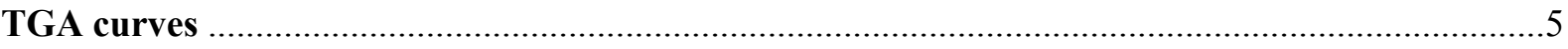

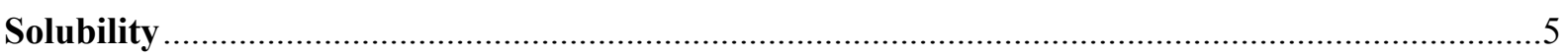

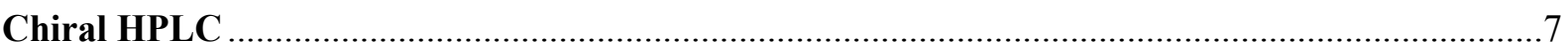

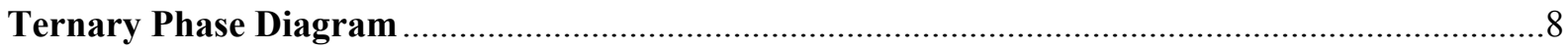

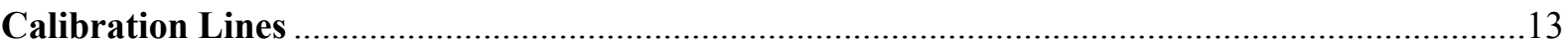

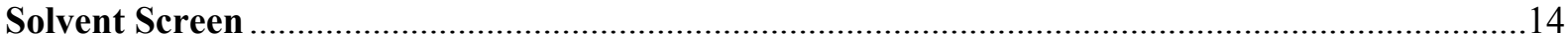

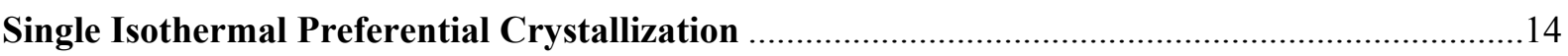

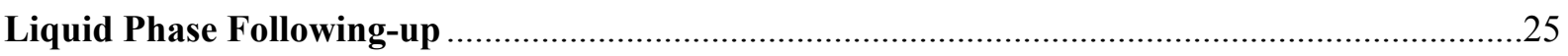

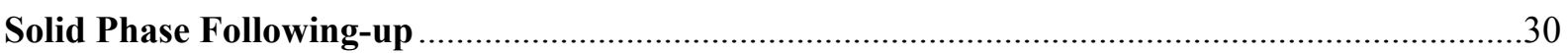

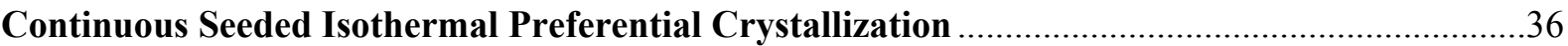




\section{Crystal Structures}

Table S1. Main crystallographic data of NRMA and refinement parameters. Crystal Structure resolved from a crystal picked up coming from *a Nefiracetam-(RS)-Mandelic acid evaporative experiment and * a Nefiracetam-(R)-Mandelic acid evaporative experiment.

\begin{tabular}{|c|c|c|}
\hline Compound & NRMA* & NRMA** \\
\hline Empirical formula & $\mathrm{C}_{22} \mathrm{H}_{26} \mathrm{~N}_{2} \mathrm{O}_{5}$ & $\mathrm{C}_{22} \mathrm{H}_{26} \mathrm{~N}_{2} \mathrm{O}_{5}$ \\
\hline Formula weight $\left(\mathrm{g} \cdot \mathrm{mol}^{-1}\right)$ & 398.45 & 398.45 \\
\hline Temperature (K) & 295(2) & $295(2)$ \\
\hline Wavelength $(\AA)$ & 1.54184 & 1.54184 \\
\hline Crystal system & Orthorhombic & Orthorhombic \\
\hline Space group & $P 2_{1} 2_{1} 2_{1}$ & $P 2_{1} 2_{1} 2_{1}$ \\
\hline $\mathrm{a}, \mathrm{b}, \mathrm{c}(\AA)$ & $\begin{array}{l}6.01624(12), 9.23442(16), \\
37.7189(6)\end{array}$ & $\begin{array}{l}6.01055(9), 9.23597(14), \\
37.7607(5)\end{array}$ \\
\hline$\alpha, \beta, \gamma\left({ }^{\circ}\right)$ & $90,90,90$ & $90,90,90$ \\
\hline Volume $\left(\AA^{3}\right)$ & $2095.53(6)$ & $2096.21(5)$ \\
\hline $\mathrm{Z}$ & 4 & 4 \\
\hline Density $\left(\mathrm{g} . \mathrm{cm}^{-3}\right)$ & 1.263 & 1.263 \\
\hline Absorption coefficient $\left(\mathrm{mm}^{-1}\right)$ & 0.737 & 0.737 \\
\hline $\mathrm{F}(000)$ & 848 & 848 \\
\hline Crystal size $\left(\mathrm{mm}^{3}\right)$ & $0.550 \times 0.480 \times 0.190$ & $0.470 \times 0.330 \times 0.270$ \\
\hline $\begin{array}{l}\text { Theta range for data collection } \\
\left({ }^{\circ}\right)\end{array}$ & 2.343 to 67.092 & 4.684 to 67.062 \\
\hline Reflections collected & 10110 & 10293 \\
\hline Completeness to $\theta=67.092^{\circ}$ & $99.1 \%$ & $98.8 \%$ \\
\hline Max. and min. transmission & 0.880 and 0.733 & 0.845 and 0.769 \\
\hline Refinement method & Full-matrix least-squares on $\mathrm{F}^{2}$ & Full-matrix least-squares on $\mathrm{F}^{2}$ \\
\hline Data / restraints / parameters & $3694 / 0 / 271$ & $3690 / 0 / 276$ \\
\hline Goodness-of-fit on $\mathrm{F}^{2}$ & 1.043 & 1.068 \\
\hline Final $R$ indices $[\mathrm{I}>2 \operatorname{sigma}(\mathrm{I})]$ & $\mathrm{R} 1=0.0375, \mathrm{wR} 2=0.0989$ & $\mathrm{R} 1=0.0303, \mathrm{wR} 2=0.0827$ \\
\hline $\mathrm{R}$ indices (all data) & $\mathrm{R} 1=0.0400, \mathrm{wR} 2=0.1017$ & $\mathrm{R} 1=0.0311, \mathrm{wR} 2=0.0836$ \\
\hline Absolute structure parameter & $-0.03(10)$ & $-0.07(6)$ \\
\hline$\Delta \rho(\max , \min )\left(\mathrm{e} . \AA^{-3}\right)$ & 0.150 and -0.139 & 0.112 and -0.088 \\
\hline
\end{tabular}

\section{Binary Phase Diagram}


Table S2. Data used to build the Nefiracetam-Mandelic acid Binary Phase diagram.

\begin{tabular}{cccc}
\hline Ratio N/RSMA & Ratio RMA/SMA & $\mathbf{T}_{\text {onset }}\left({ }^{\circ} \mathbf{C}\right)$ & $\mathbf{T}_{\text {endset }}\left({ }^{\circ} \mathbf{C}\right)$ \\
\hline 0.982 & 0.000 & 114.10 & 118.88 \\
1.001 & 0.103 & 97.29 & 114.90 \\
0.961 & 0.203 & 96.87 & 111.93 \\
1.008 & 0.304 & 98.25 & 109.18 \\
1.011 & 0.401 & 98.16 & 104.53 \\
0.983 & 0.500 & 97.64 & 97.64 \\
0.992 & 0.652 & 97.79 & 107.60 \\
1.002 & 0.704 & 98.39 & 108.75 \\
1.006 & 0.824 & 97.43 & 112.88 \\
1.004 & 0.908 & 95.68 & 115.35 \\
0.989 & 1.000 & 114.10 & 118.17 \\
\hline
\end{tabular}

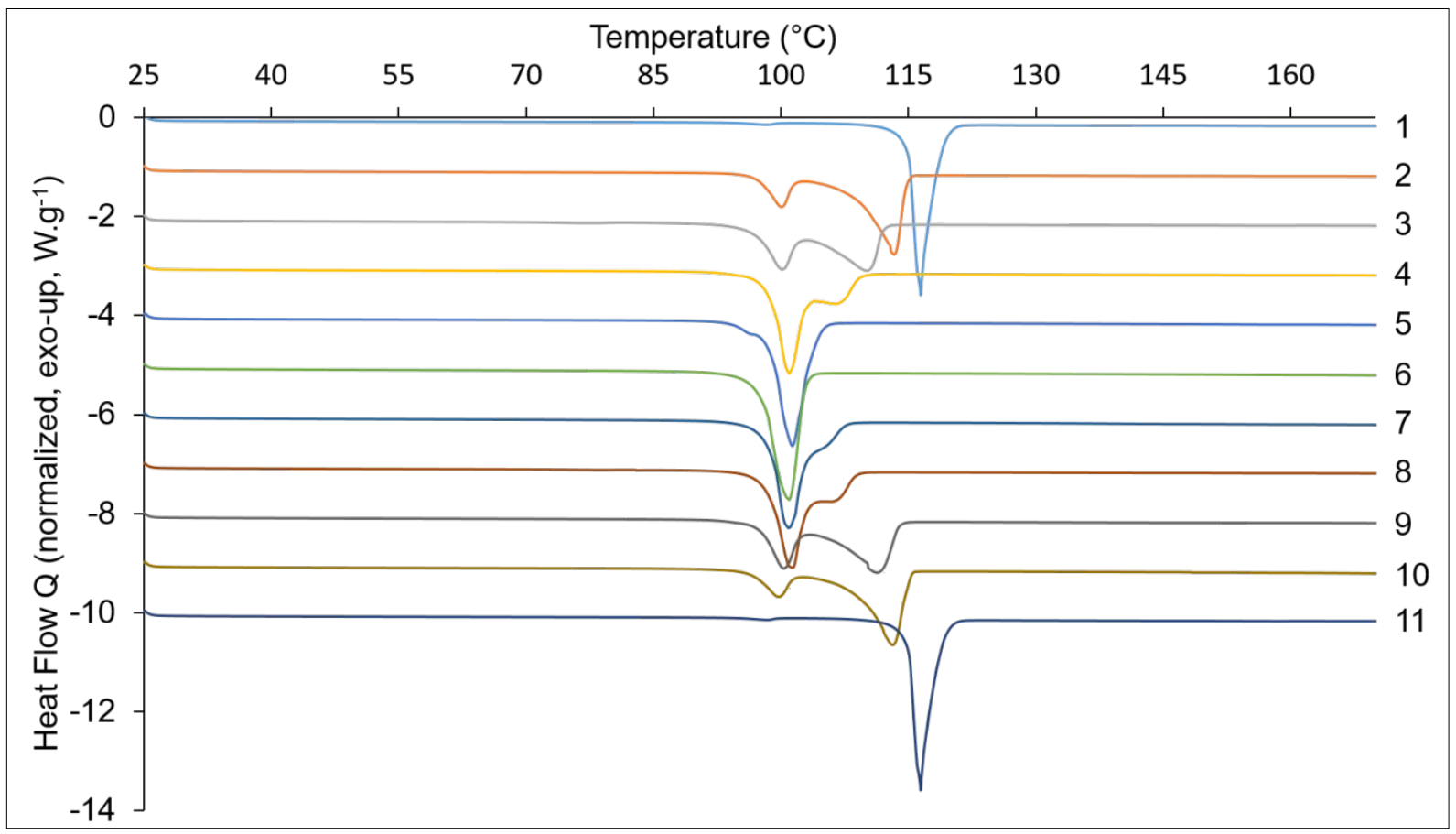

Figure S1. DSC curves related to each sample prepared for the Binary Phase Diagram construction. 


\section{TGA curves}

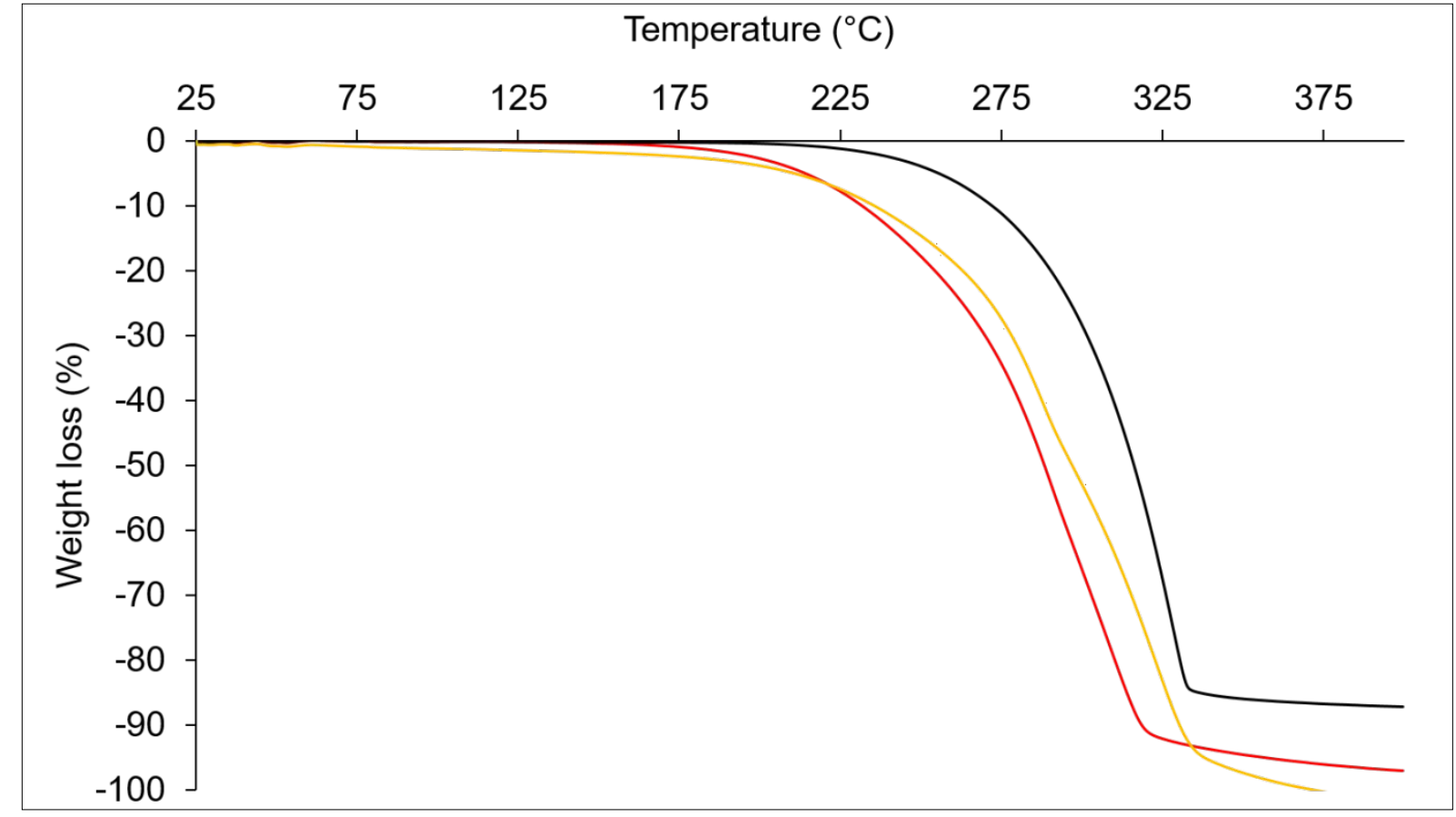

Figure S2. TGA curves of Nefiracetam FI (black), NRSMA (orange) and NRMA (red).

\section{Solubility}

$$
\begin{gathered}
\mathrm{NRSMA} \rightleftarrows \mathrm{N}+\mathrm{RSMA} \\
\mathrm{Ks}=[\mathrm{RSMA}] \times[\mathrm{N}] \\
\ln \mathrm{Ks}=-\frac{\Delta \mathrm{H}_{\text {diss }}}{\mathrm{RT}}+\frac{\Delta \mathrm{S}_{\text {diss }}}{\mathrm{R}}
\end{gathered}
$$




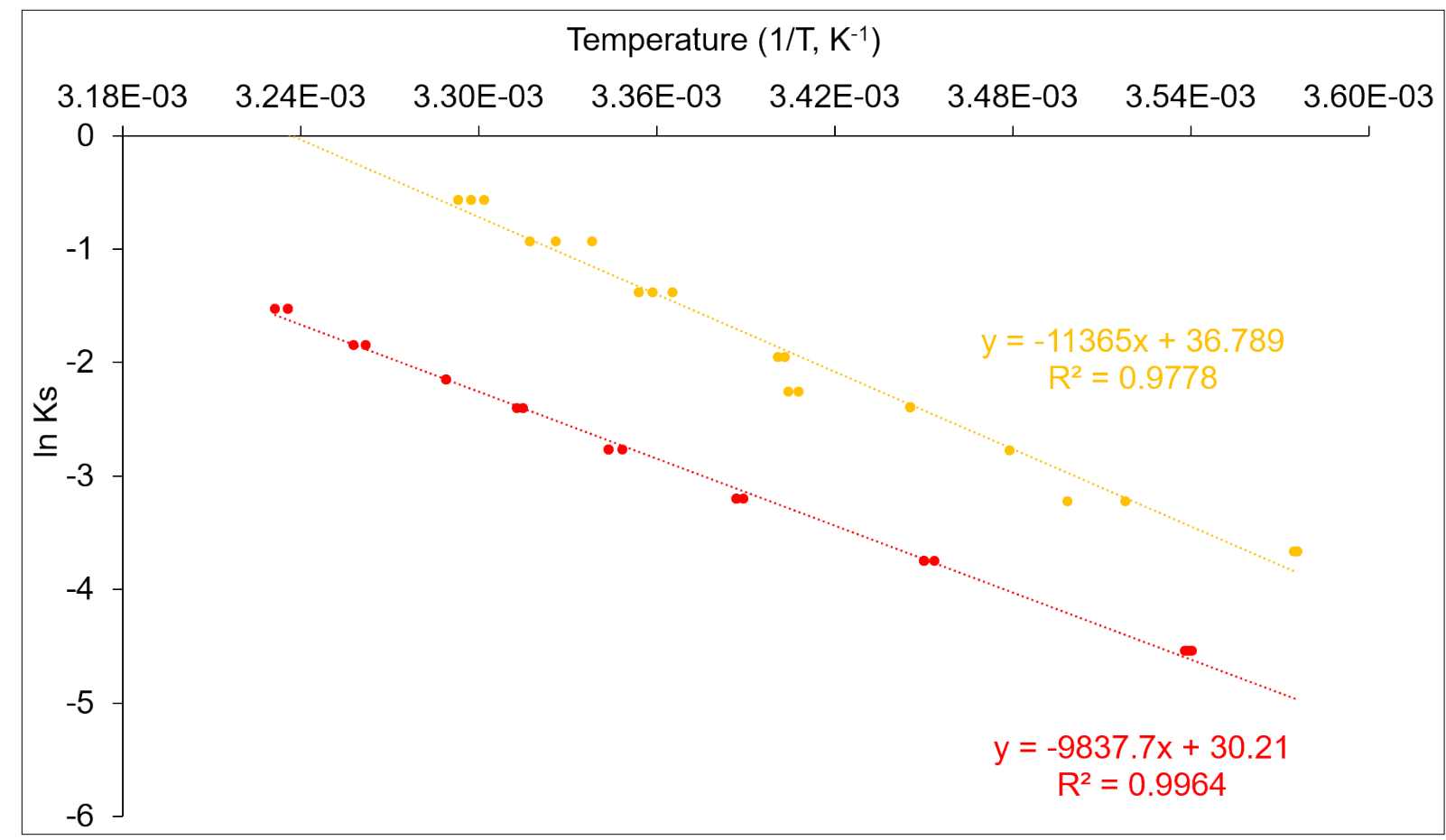

Figure S3. Van't Hoff plot of the solubility curves of NRSMA (orange) and NRMA (red) in MeCN. The lines are not fully parallel which can be explained by experimental error, or by deviation of ideality (intermolecular interactions between opposite enantiomers differs from that of identical enantiomers at higher concentration) 


\section{Chiral HPLC}
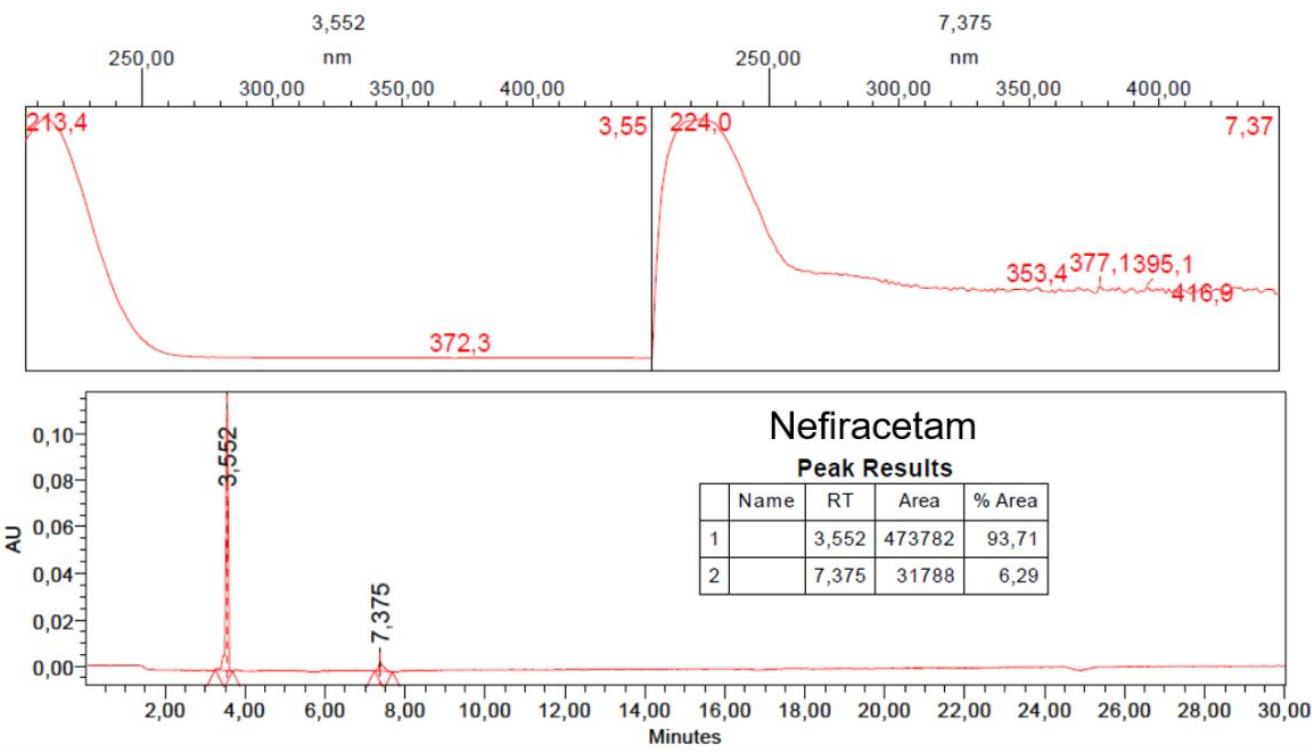

10,013
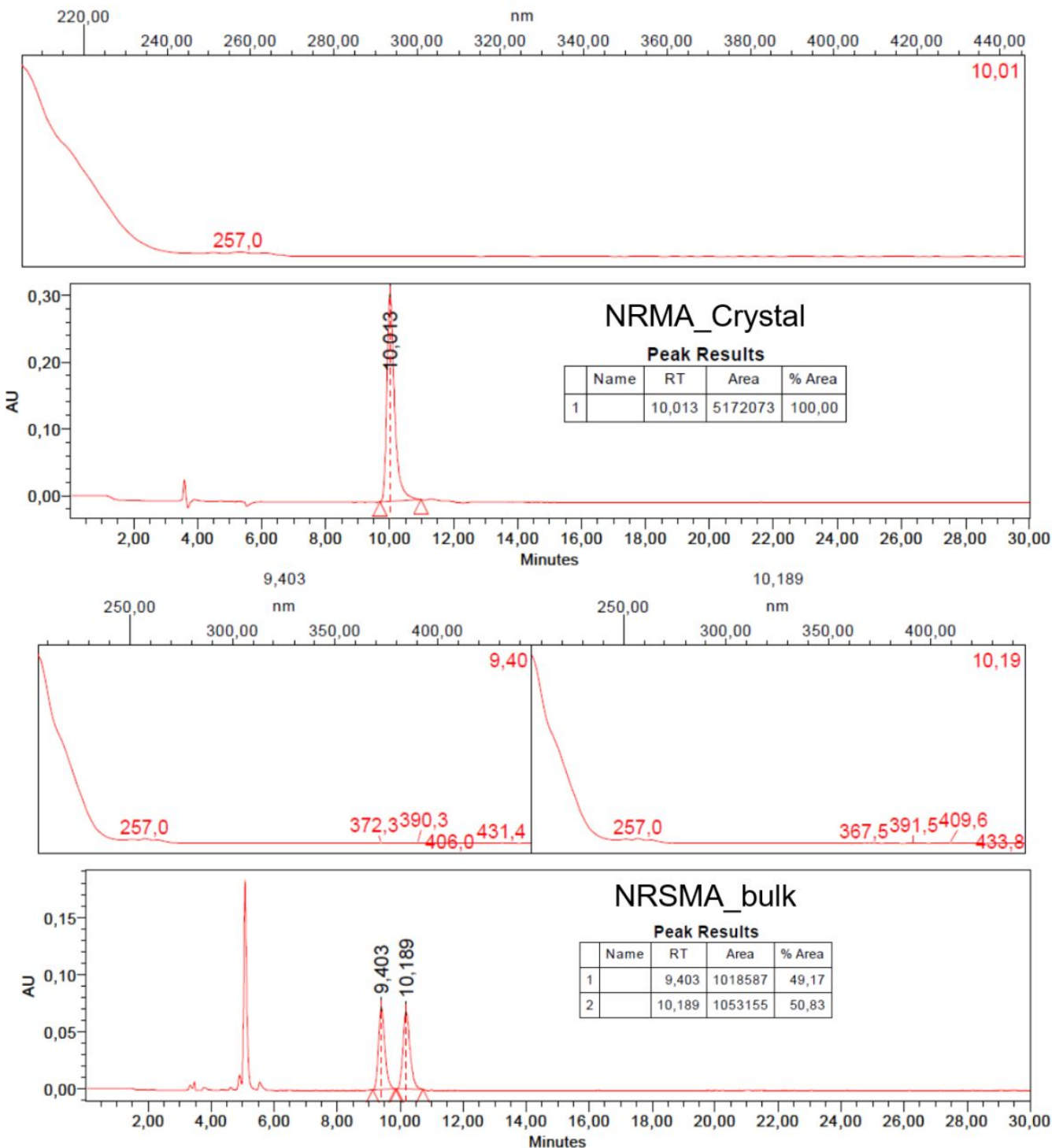

Figure S4. UV Spectrum index plot and chiral HPLC chromatogram of Nefiracetam, NRMA (crystal) and NRSMA (bulk material). 


\section{Ternary Phase Diagram}

Table S3. Mass fractions (S, R enantiomer and solvent) calculated to build the Ternary Phase Diagram.

\begin{tabular}{cccc}
\hline Samples & Mass fraction S & Mass fraction R & Mass fraction Solvent \\
\hline 1 & $9.60 \times 10^{-2}$ & 0 & $9.04 \times 10^{-1}$ \\
2 & $1.12 \times 10^{-1}$ & $2.66 \times 10^{-2}$ & $8.61 \times 10^{-1}$ \\
3 & $1.18 \times 10^{-1}$ & $5.66 \times 10^{-2}$ & $8.25 \times 10^{-1}$ \\
4 & $1.07 \times 10^{-1}$ & $1.04 \times 10^{-1}$ & $7.89 \times 10^{-1}$ \\
5 & $1.07 \times 10^{-1}$ & $1.03 \times 10^{-1}$ & $7.90 \times 10^{-1}$ \\
6 & $1.04 \times 10^{-1}$ & $1.02 \times 10^{-1}$ & $7.94 \times 10^{-1}$ \\
7 & $1.10 \times 10^{-1}$ & $1.08 \times 10^{-1}$ & $7.83 \times 10^{-1}$ \\
8 & $1.13 \times 10^{-1}$ & $1.15 \times 10^{-1}$ & $7.72 \times 10^{-1}$ \\
9 & $5.38 \times 10^{-2}$ & $1.05 \times 10^{-1}$ & $8.41 \times 10^{-1}$ \\
10 & $2.34 \times 10^{-2}$ & $1.06 \times 10^{-1}$ & $8.71 \times 10^{-1}$ \\
11 & 0 & $1.06 \times 10^{-1}$ & $8.94 \times 10^{-1}$ \\
\hline
\end{tabular}

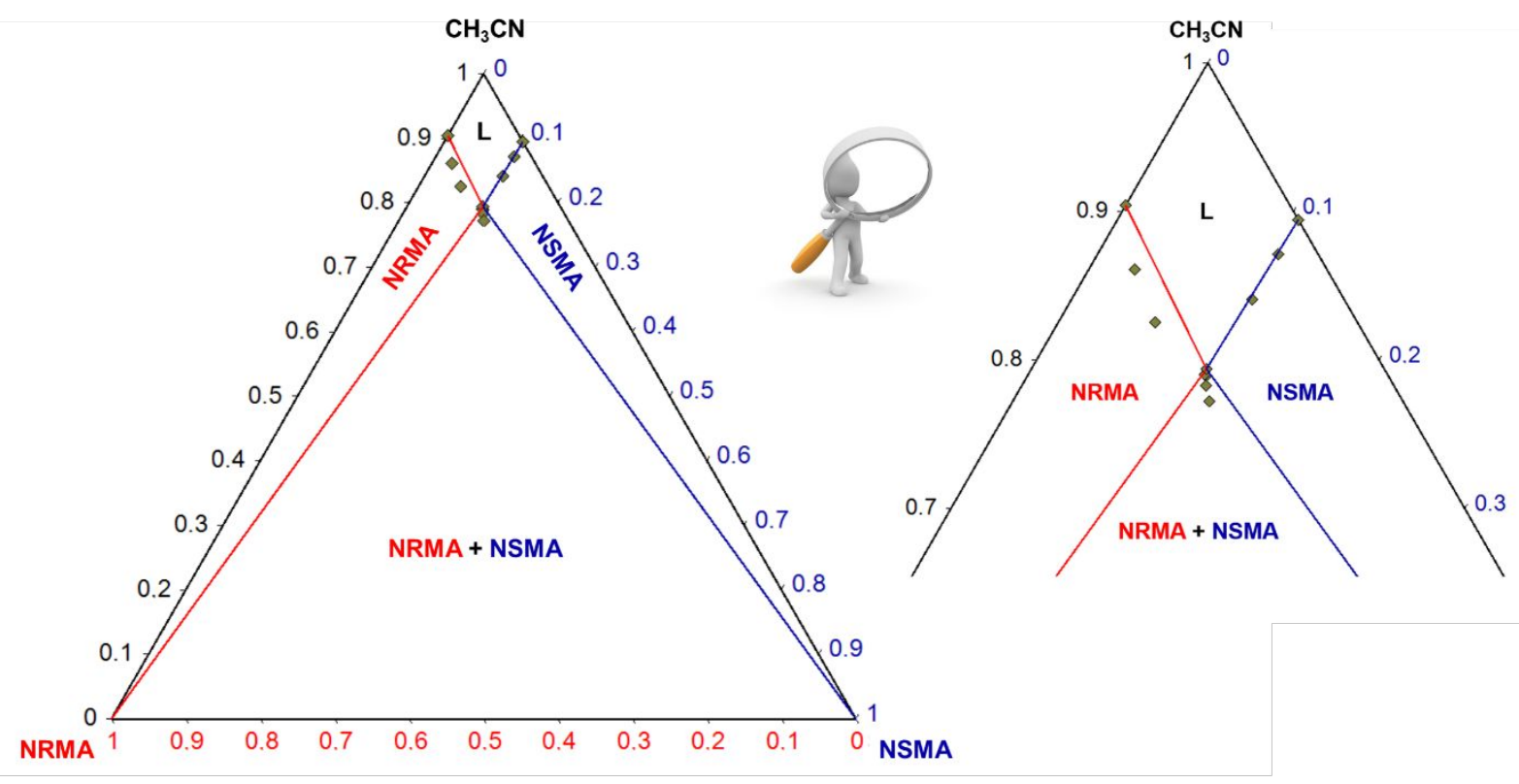

Figure S5. Ternary Phase Diagram (isothermal cut) of Nefiracetam-Mandelic acid in $\mathrm{MeCN}$ at $23^{\circ} \mathrm{C}$. 

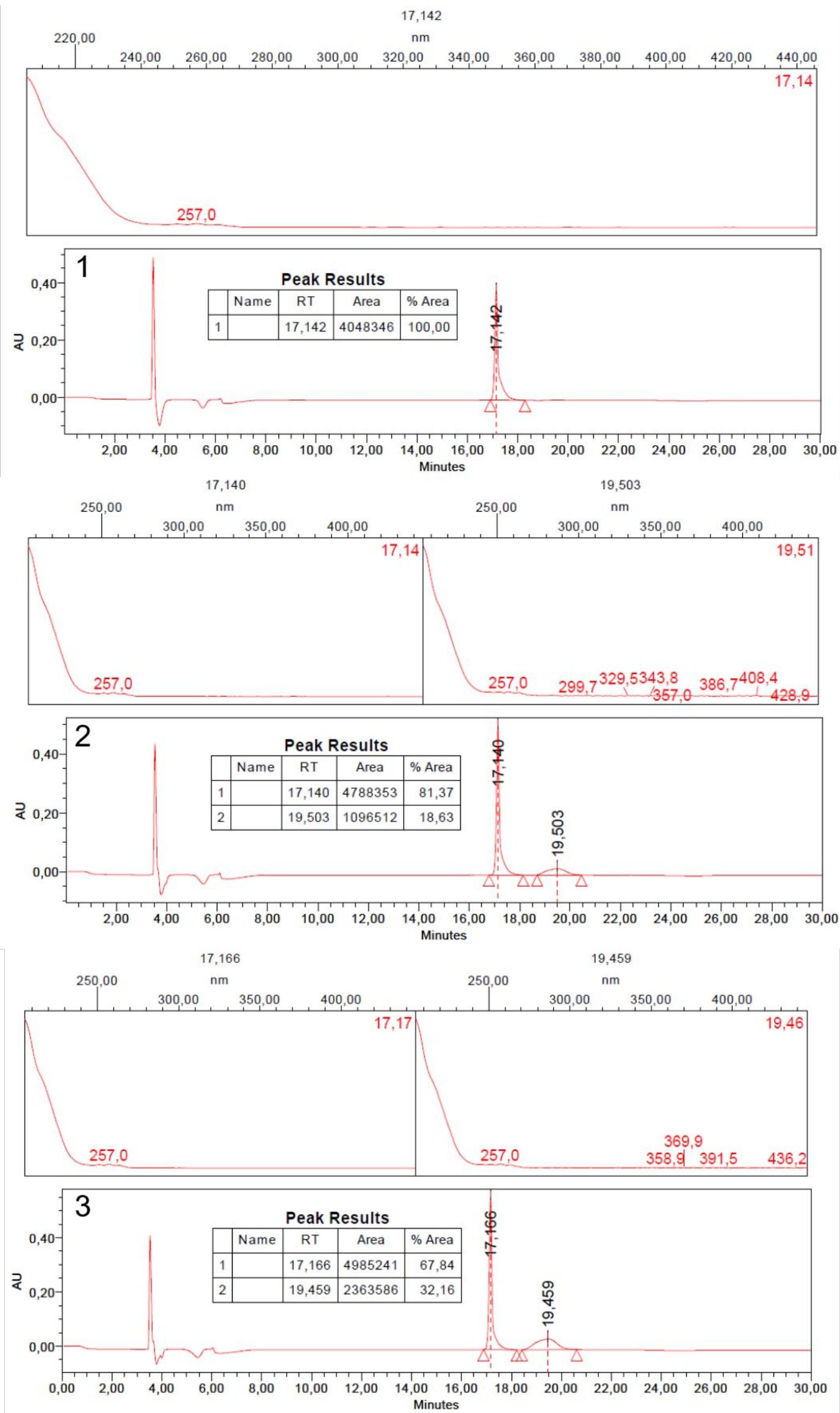

Figure S6. UV Spectrum index plot and chiral HPLC chromatogram related to the liquid fractions $(1,2$ and 3$)$ and required for the Ternary Phase Diagram construction. 

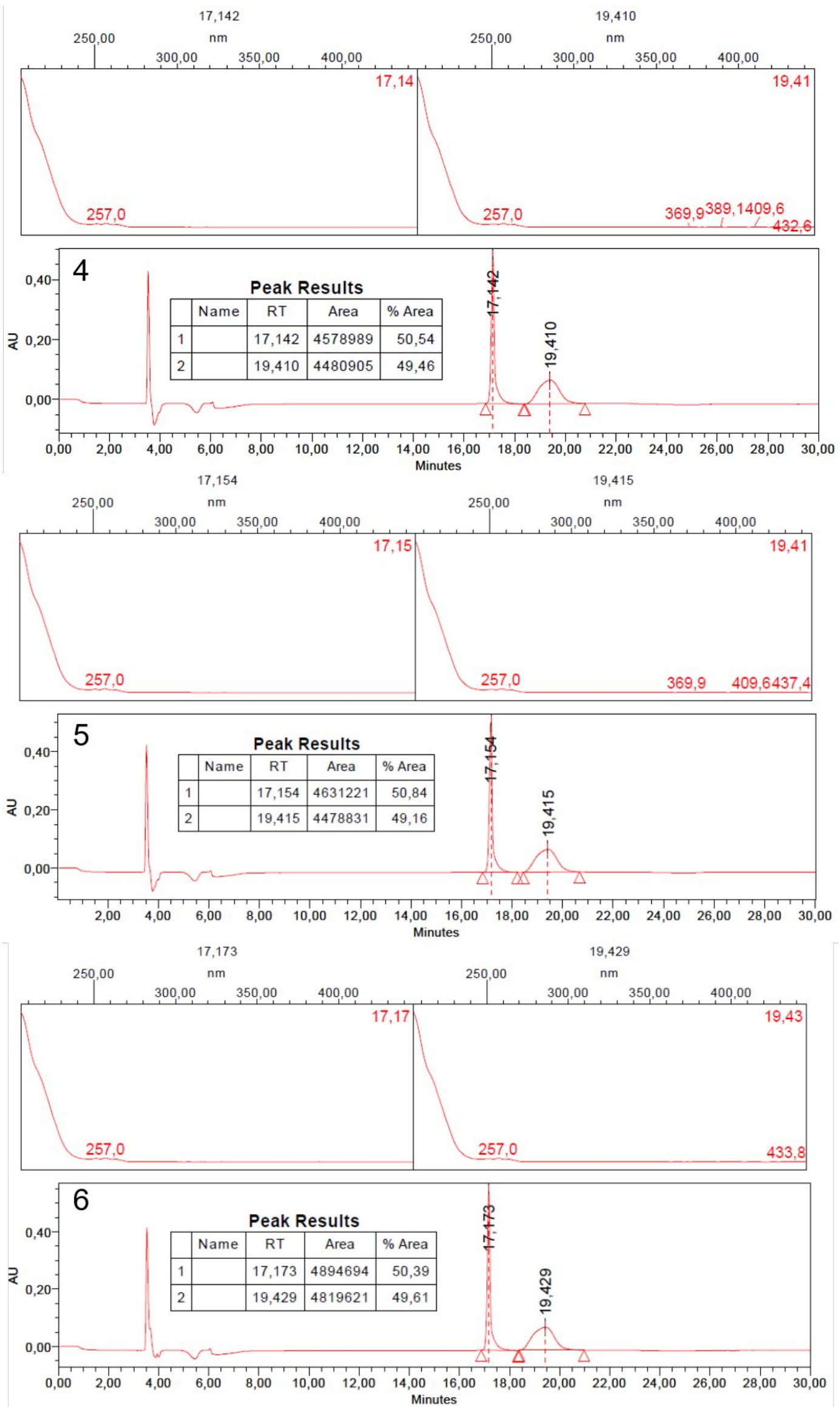

Figure S7. UV Spectrum index plot and chiral HPLC chromatogram related to the liquid fractions $(4,5$ and 6$)$ and required for the Ternary Phase Diagram construction. 

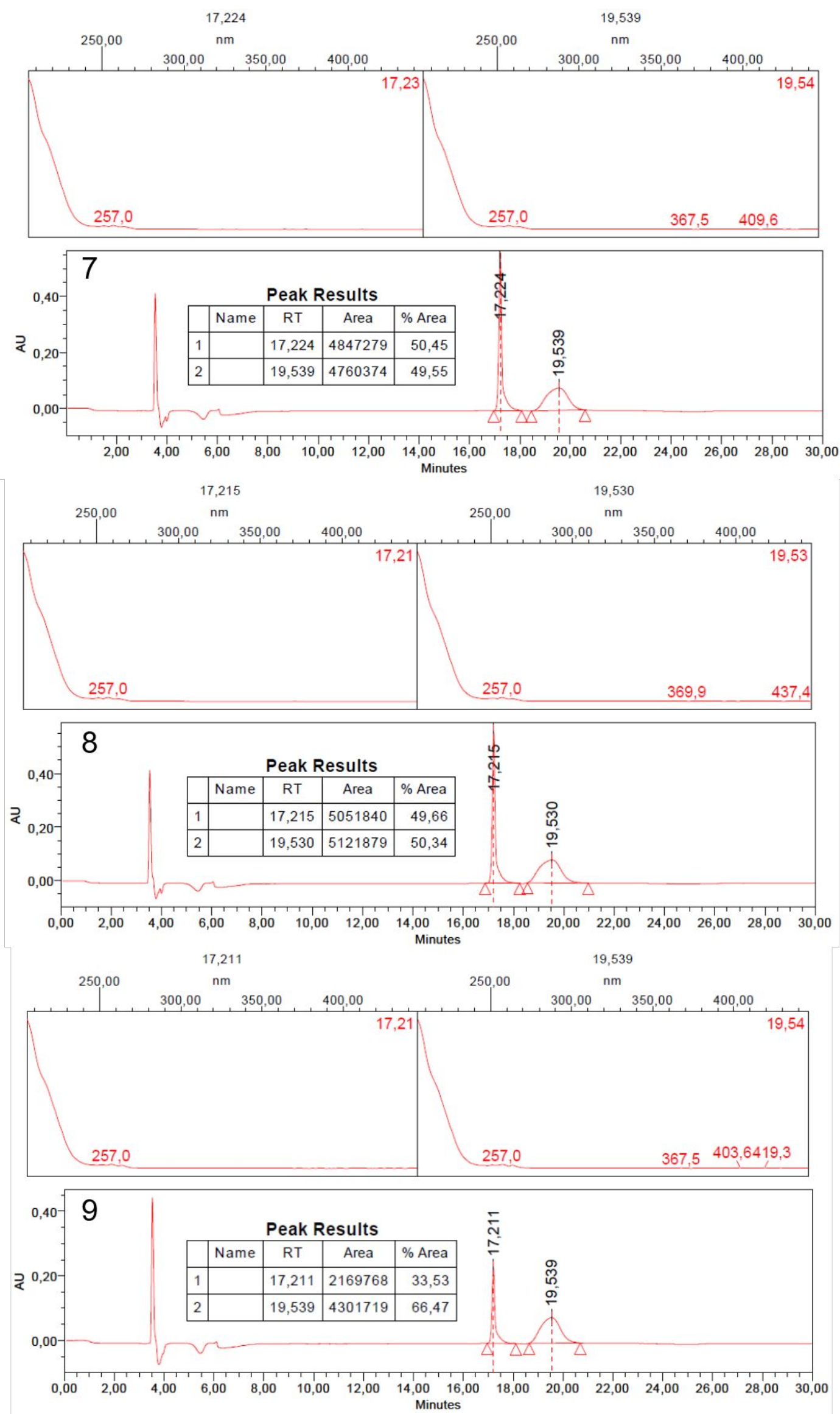

Figure S8. UV Spectrum index plot and chiral HPLC chromatogram related to the liquid fractions (7, 8 and 9$)$ and required for the Ternary Phase Diagram construction. 

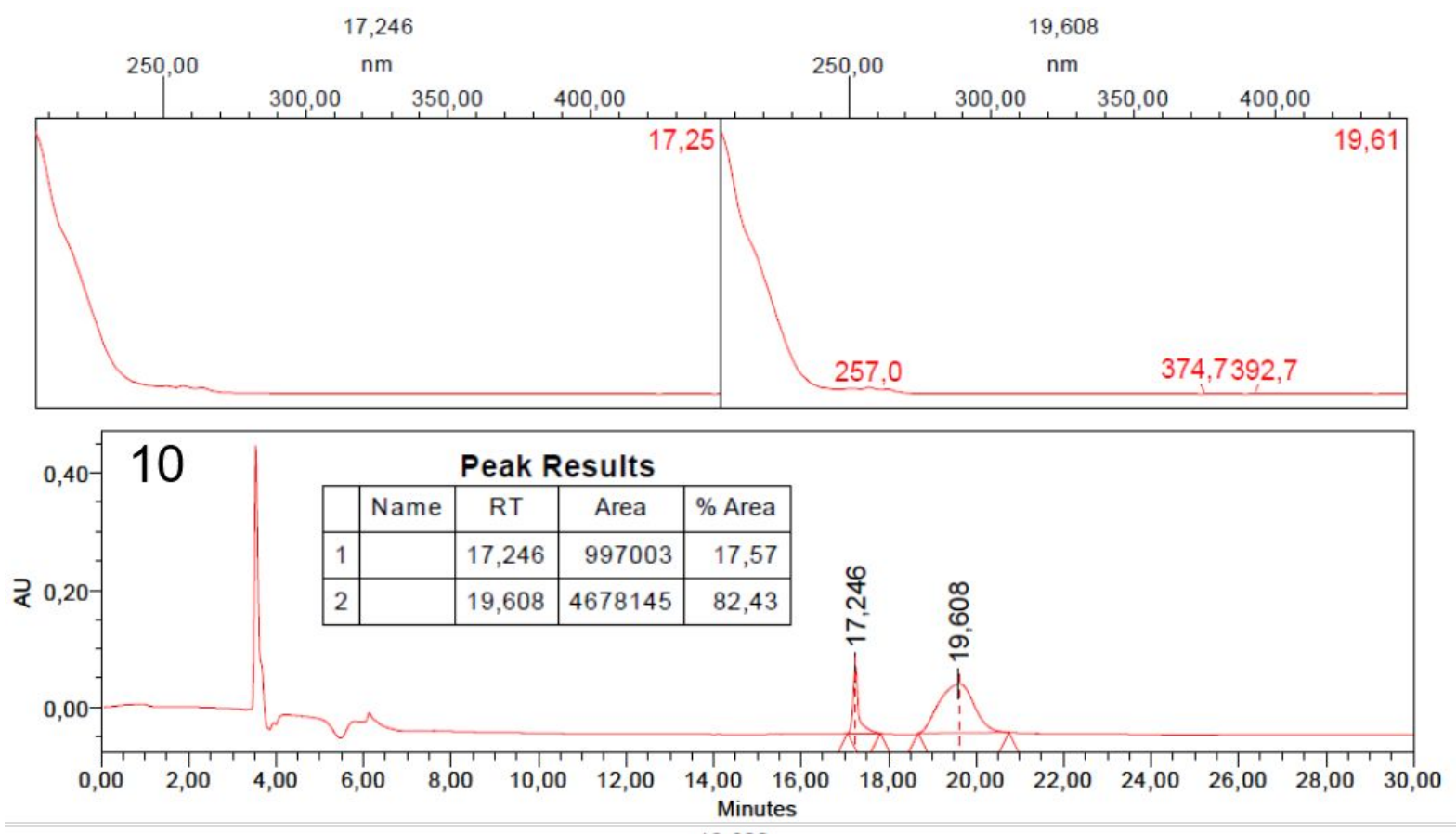

19,620
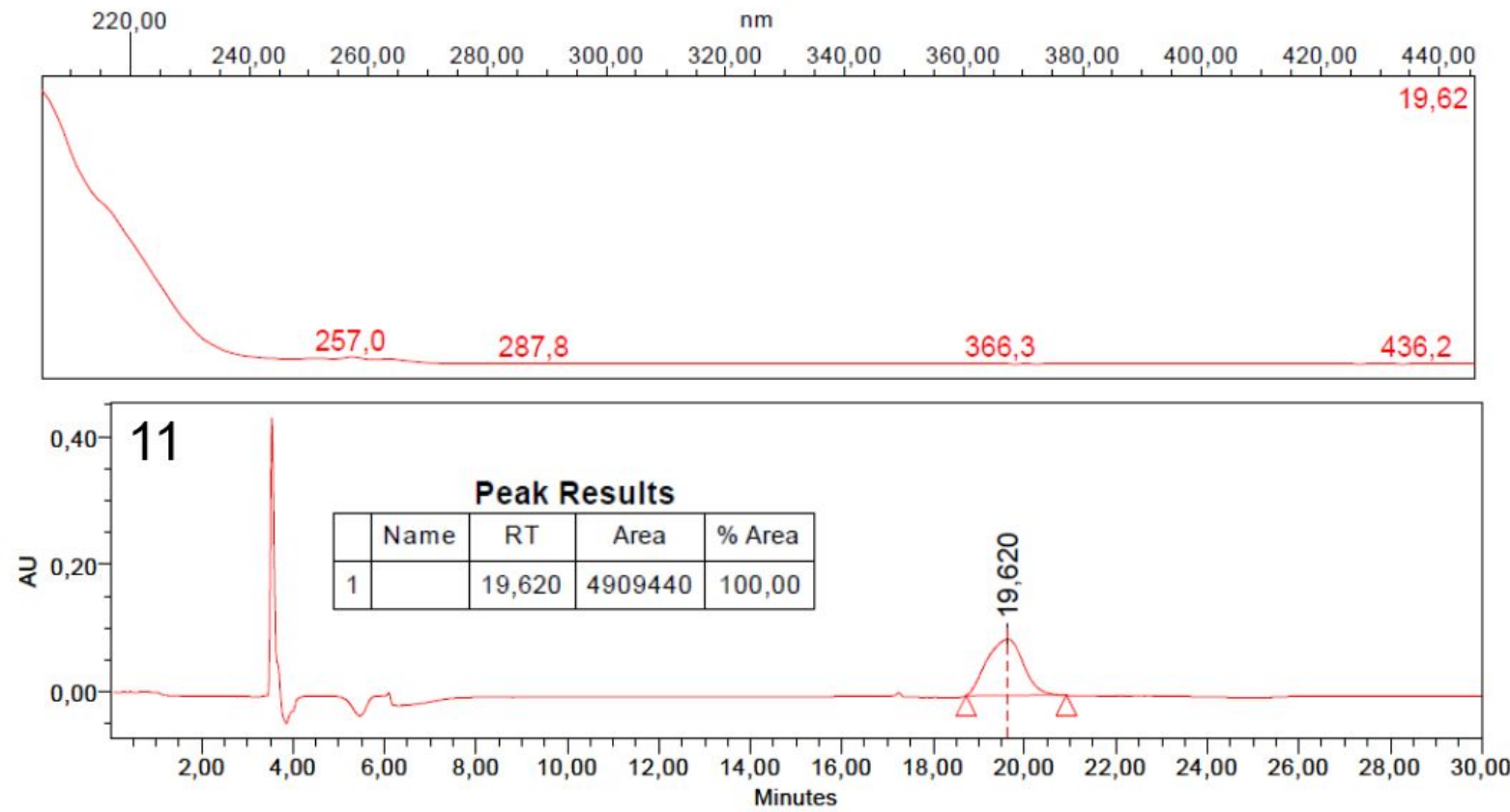

Figure S9. UV Spectrum index plot and chiral HPLC chromatogram related to the liquid fractions (10 and 11) and required for the Ternary Phase Diagram construction. 


\section{Calibration Lines}
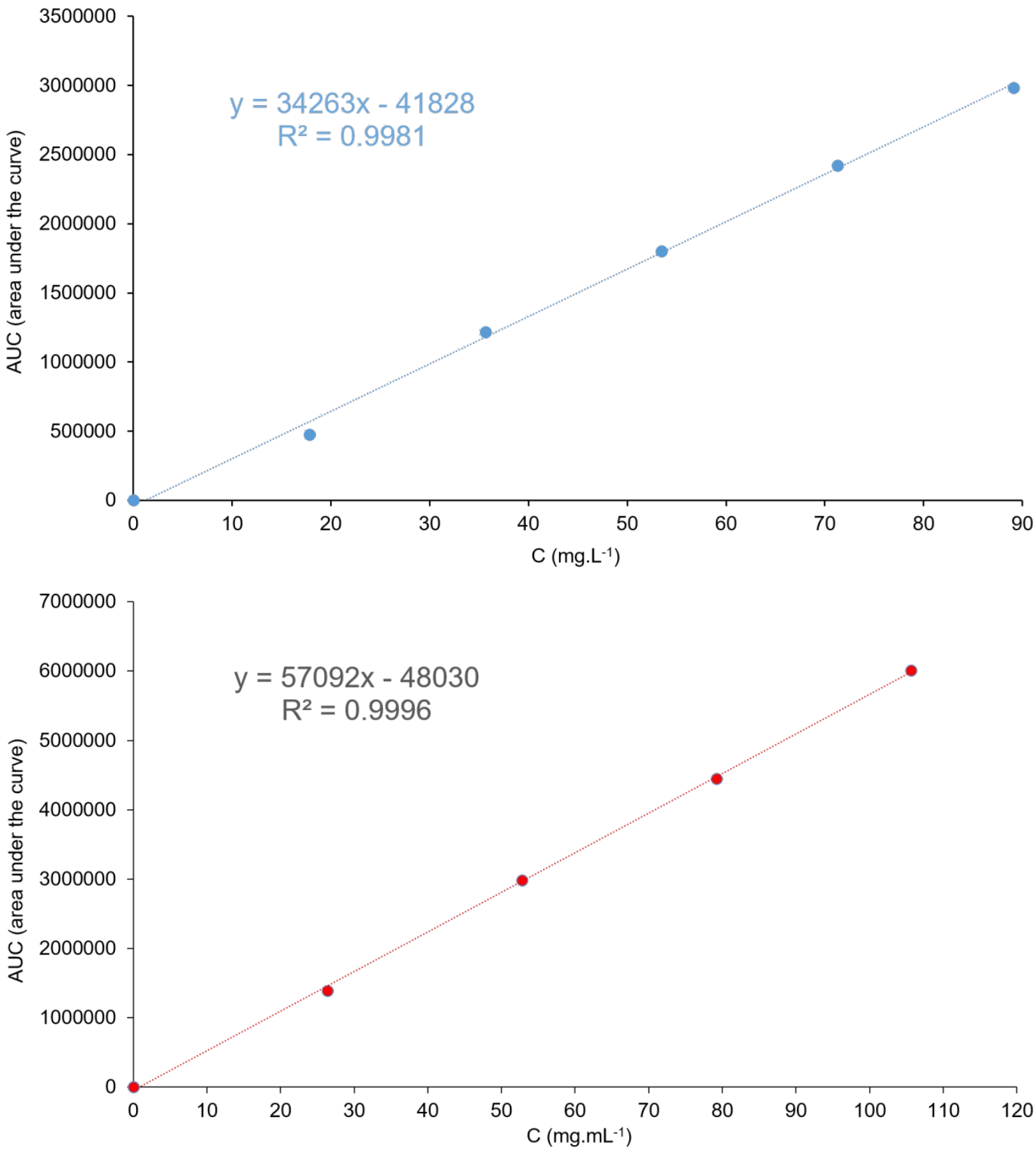

Figure S10. Calibration lines for Nefiracetam dosage in reverse HPLC (top) and RMA/SMA dosage/ratio in chiral HPLC. 


\section{Solvent Screen}

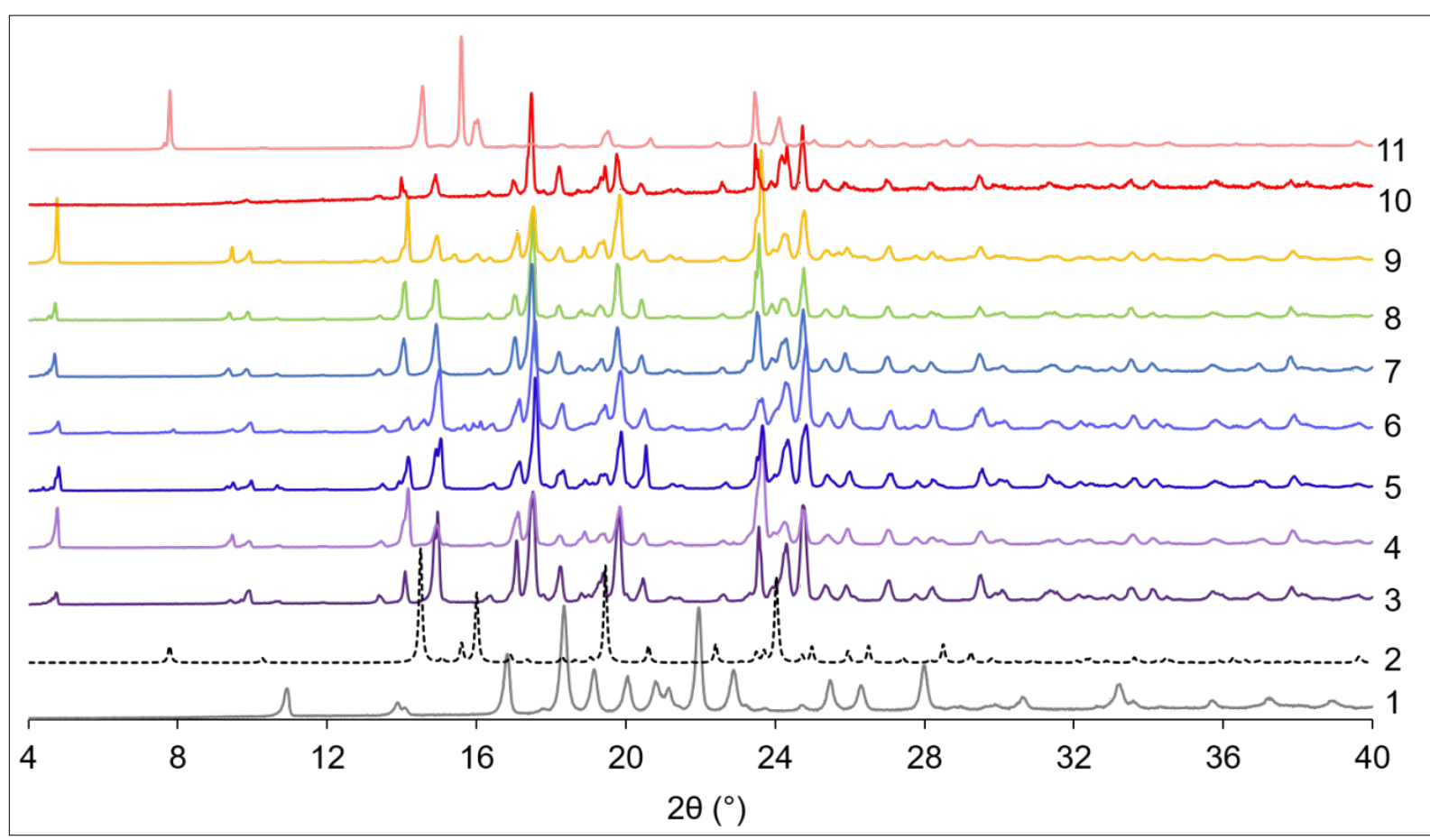

Figure S11. XRPD analyses performed on the solid outcomes obtained during the congruency experiments in (3) acetonitrile, (4) chloroform, (5) dichloromethane, (6) diethylether, (7) ethyl acetate, (8) ethanol, (9) water, (10) 2-propanol and (11). They are compared to the (1) Nefiracetam FI simulated pattern and (2) the (RS)-mandelic acid experimental one.

\section{Single Isothermal Preferential Crystallization}

Table S4. Process parameters and results of the 7 other SIPC trials.

\begin{tabular}{llllllllll}
\hline $\mathbf{N}^{\circ}$ & $\begin{array}{c}\mathbf{P C} \\
\mathbf{M o d e}\end{array}$ & $\begin{array}{c}\mathbf{V} \\
(\mathbf{m L})\end{array}$ & $\begin{array}{c}\mathbf{T} 1 \\
\left({ }^{\circ} \mathbf{C}\right)\end{array}$ & $\begin{array}{c}\mathbf{T 2} \\
\left({ }^{\circ} \mathbf{C}\right)\end{array}$ & $\begin{array}{c}\text { Cooling } \\
\text { rate } \\
\left({ }^{\circ} \mathbf{C . m i n}-\mathbf{m}\right)\end{array}$ & $\begin{array}{c}\mathbf{t}_{\text {end }} \\
(\mathbf{m i n})\end{array}$ & $\begin{array}{c}\text { mass } \\
\text { NRSMA } \\
(\mathbf{g})\end{array}$ & $\begin{array}{c}\text { mass } \\
\text { seed } \\
(\mathbf{m g})\end{array}$ & $\begin{array}{c}\mathbf{m} \text { end } \\
(\mathbf{m g})\end{array}$ \\
\hline 9 & SIPC & 50 & 20 & 17 & $\mathrm{n} / \mathrm{a}$ & 120 & 8.50 & 52.61 & 226.40 \\
10 & SIPC & 50 & 20 & 19 & $\mathrm{n} / \mathrm{a}$ & 120 & 8.20 & 50.41 & 311.99 \\
11 & SIPC & 50 & 20 & 17 & $\mathrm{n} / \mathrm{a}$ & 90 & 7.50 & 50.08 & 358.52 \\
12 & SIPC & 100 & 23 & 17 & 1.7 & 60 & 21.19 & 50.19 & 726.96 \\
13 & SIPC & 100 & 23 & 17 & 1.7 & 90 & 16.71 & 50.24 & 1435.72 \\
14 & SIPC & 100 & 23 & 17 & 1.7 & 120 & 18.02 & 50.42 & 1412.2 \\
15 & SIPC & 750 & 23 & $17.3 / 17.3 *$ & 0.1 & 180 & 120.36 & 376.83 & 24902.45 \\
\hline
\end{tabular}


Table S5. Values of purity, resolution index, productivity and yield for the experiments of Table S4. Those parameters are only calculated for pure NRMA outcomes.

\begin{tabular}{lllll}
\hline $\mathbf{N}^{\circ}$ & Pu NRMA (\%) & RI & $\begin{array}{l}\text { Pr NRMA } \\
\left(\mathbf{1 0}^{-\mathbf{3}} \mathbf{g . g ^ { - 1 }} \cdot \mathbf{m i n}^{-\mathbf{1}}\right)\end{array}$ & yield (\%) \\
\hline 9 & 93.82 & 3.04 & 0.31 & 13.08 \\
10 & 86.68 & $\mathrm{n} / \mathrm{a}$ & $\mathrm{n} / \mathrm{a}$ & $\mathrm{n} / \mathrm{a}$ \\
11 & 98.46 & 5.75 & 0.90 & 42.00 \\
12 & 99.32 & 13.39 & 1.06 & 14.81 \\
13 & 82.07 & $\mathrm{n} / \mathrm{a}$ & $\mathrm{n} / \mathrm{a}$ & $\mathrm{n} / \mathrm{a}$ \\
14 & 59.89 & $\mathrm{n} / \mathrm{a}$ & $\mathrm{n} / \mathrm{a}$ & $\mathrm{n} / \mathrm{a}$ \\
15 & 50.19 & n/a & n/a & n/a \\
\hline
\end{tabular}

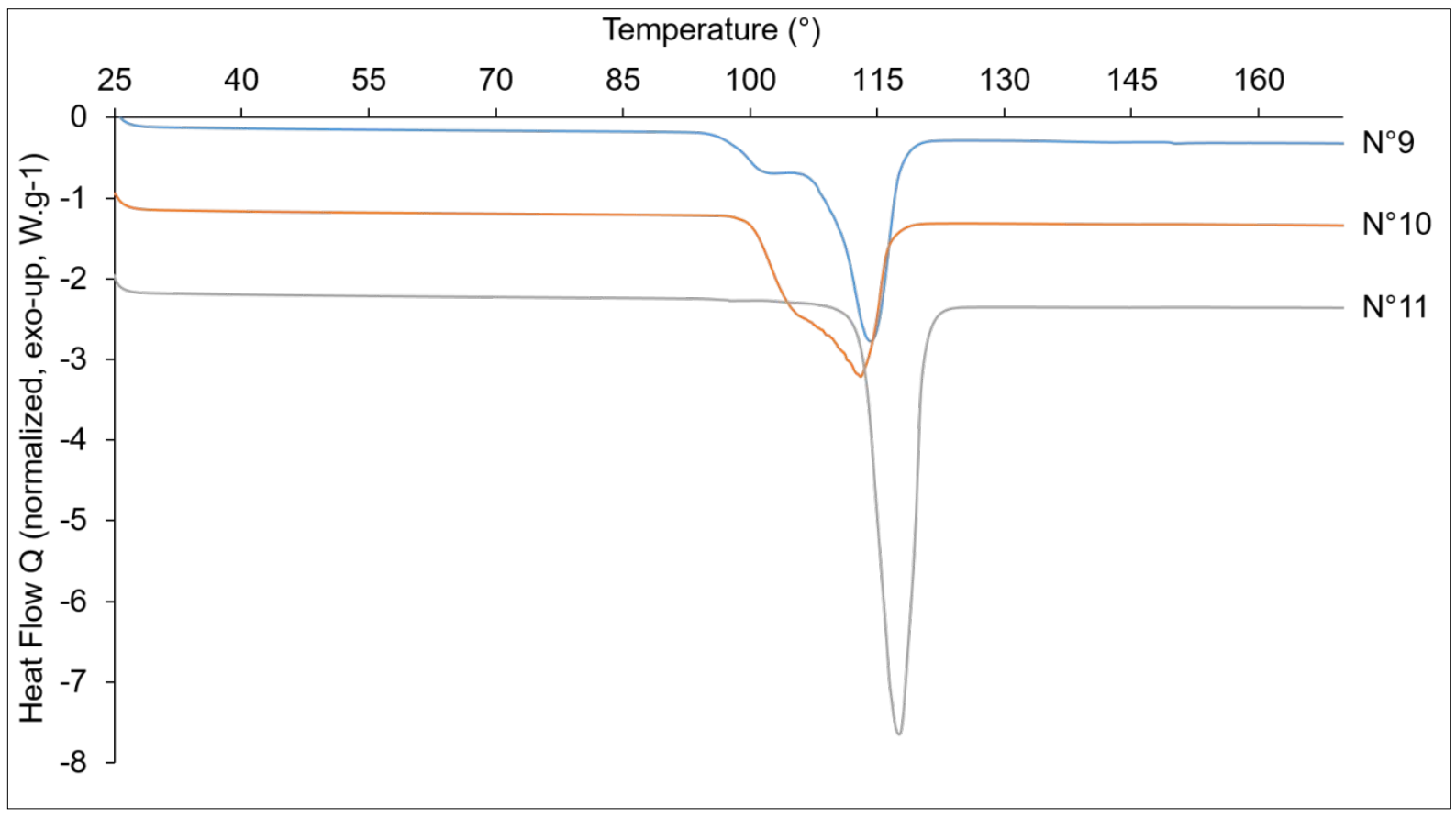

Figure S12. DSC analyses performed on the solid outcomes of the trials 9 to 11 . 


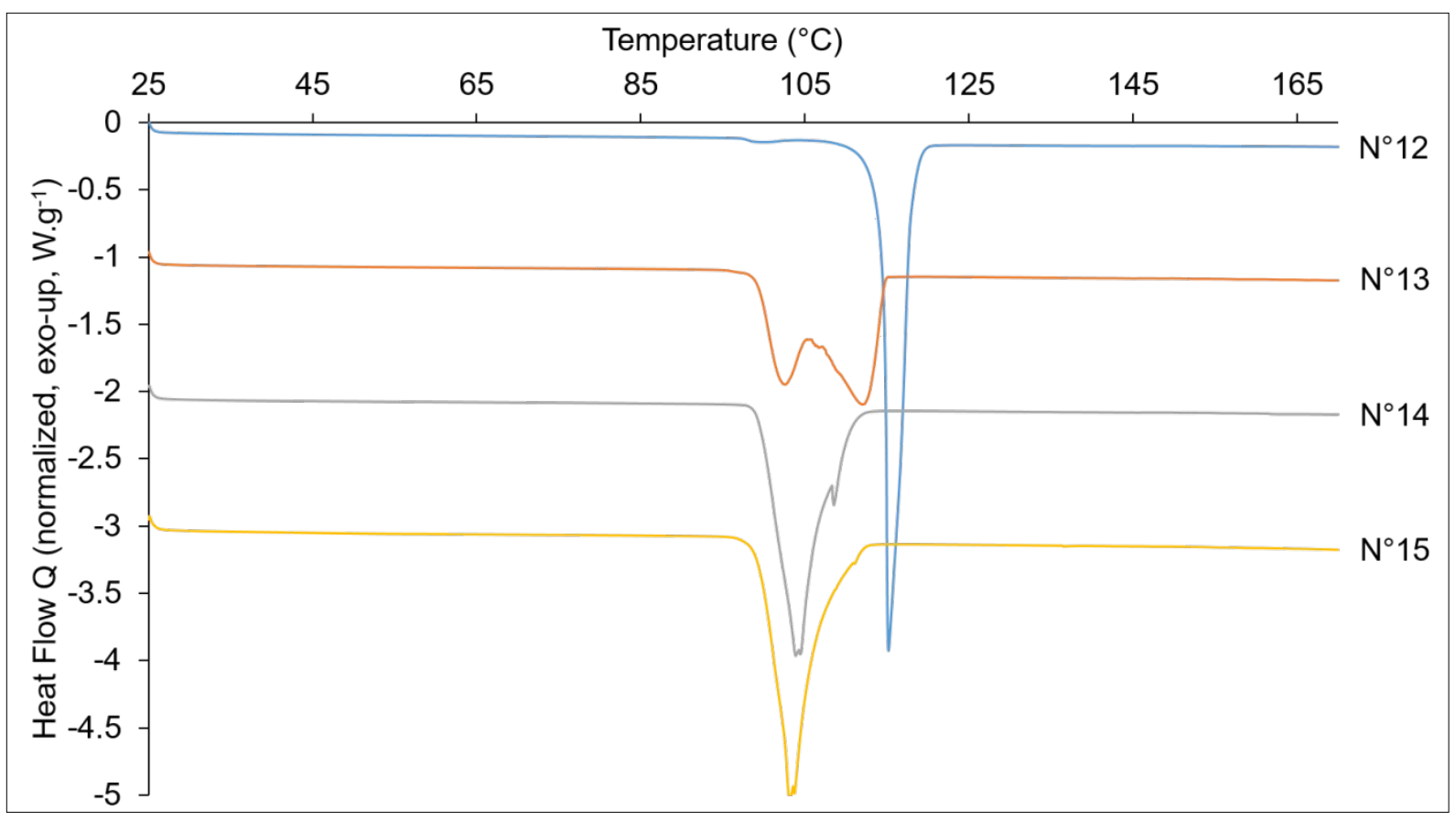

Figure S13. DSC analyses performed on the solid outcomes of the trials 12 to 15 . 

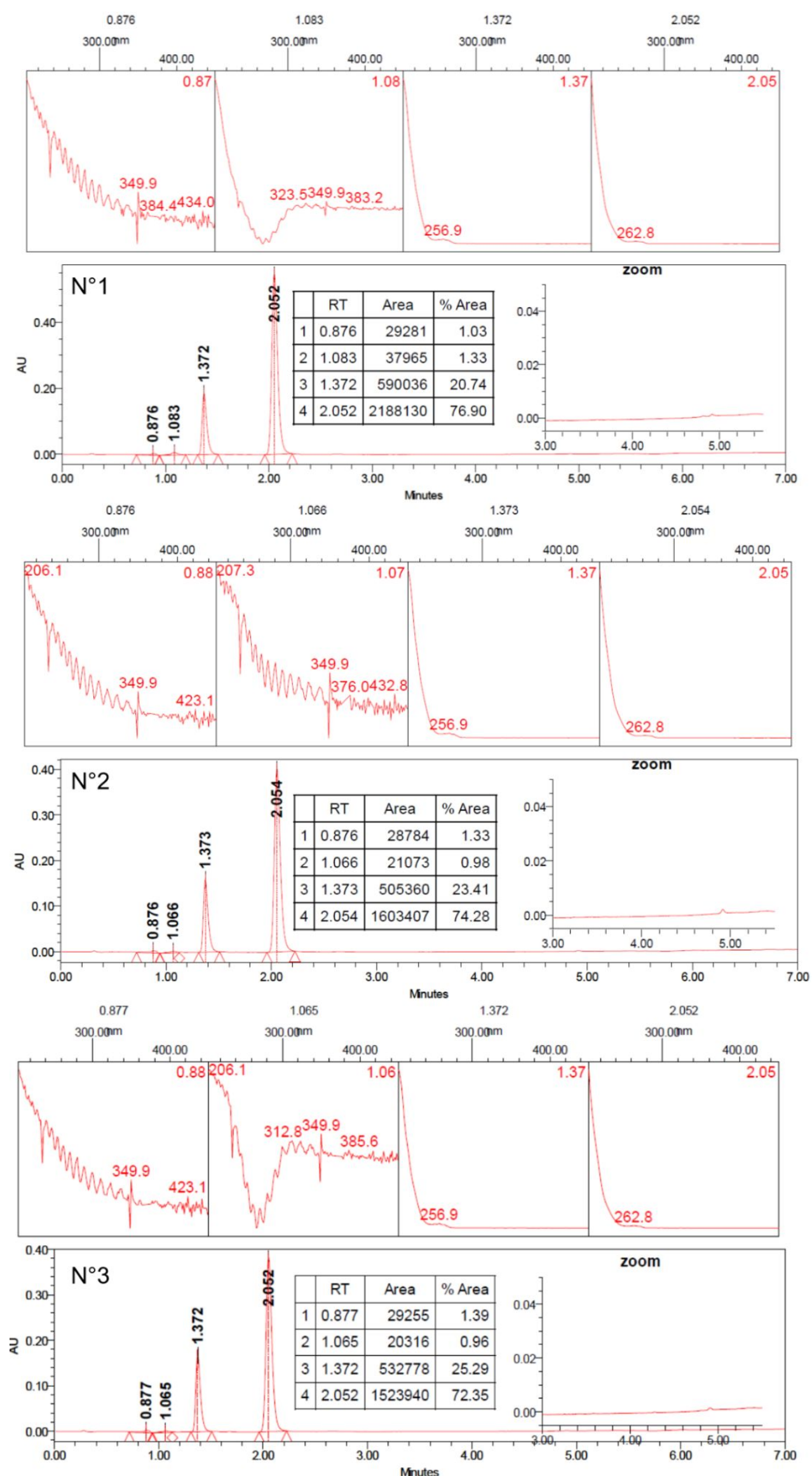

Figure S14. UV spectrum index plot and reverse HPLC chromatograms used to dose the NRSMA solubility for the trials 1 to 3. The Nefiracetam absorption peak goes out around $2.0 \mathrm{~min}$. 

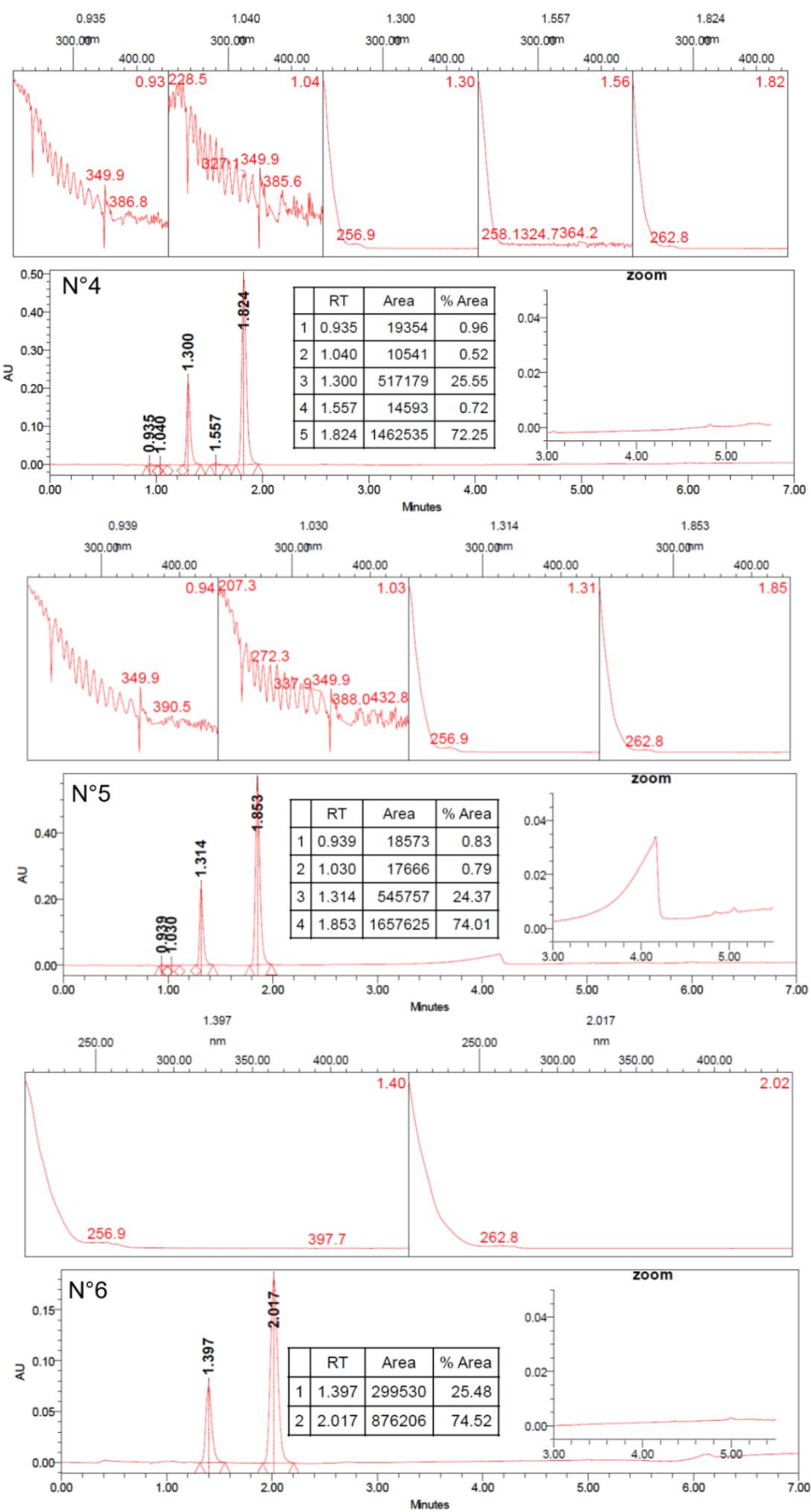

Figure S15. UV spectrum index plot and reverse HPLC chromatograms used to dose the NRSMA solubility for the trials 4 to 6. The Nefiracetam absorption peak goes out around $2.0 \mathrm{~min}$. 

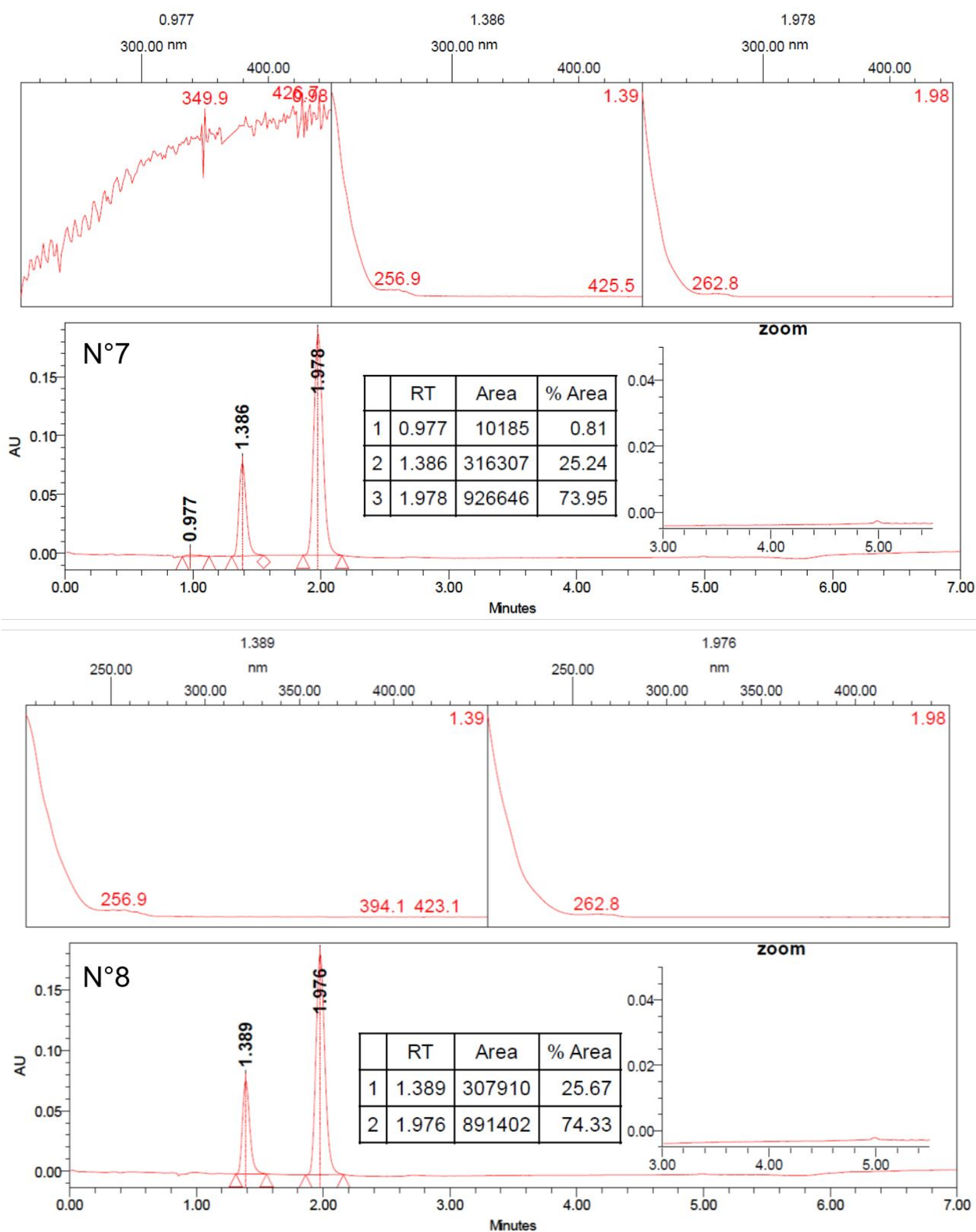

Figure S16. UV spectrum index plot and reverse HPLC chromatograms used to dose the NRSMA solubility for the trials 7 and 8 . The Nefiracetam absorption peak goes out around $2.0 \mathrm{~min}$. 

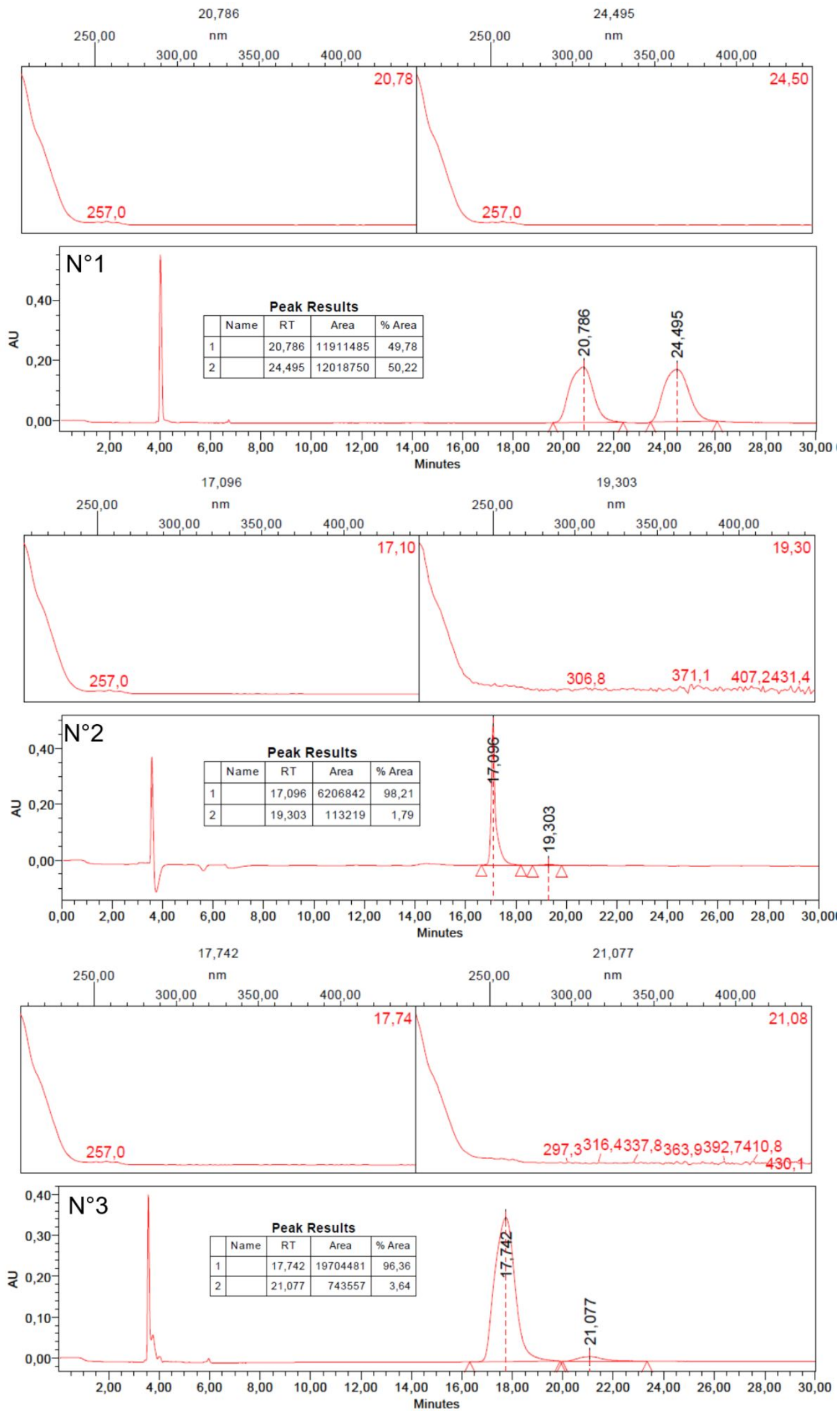

Figure S17. UV spectrum index plot and chiral HPLC chromatograms of the solid outcomes (trial $\mathrm{N}^{\circ} 1$ to $\mathrm{N}^{\circ} 3$ ). The first retention peak is associated to the solvent. The R and S-enantiopurity are given by AUC of the two integrated peaks. 

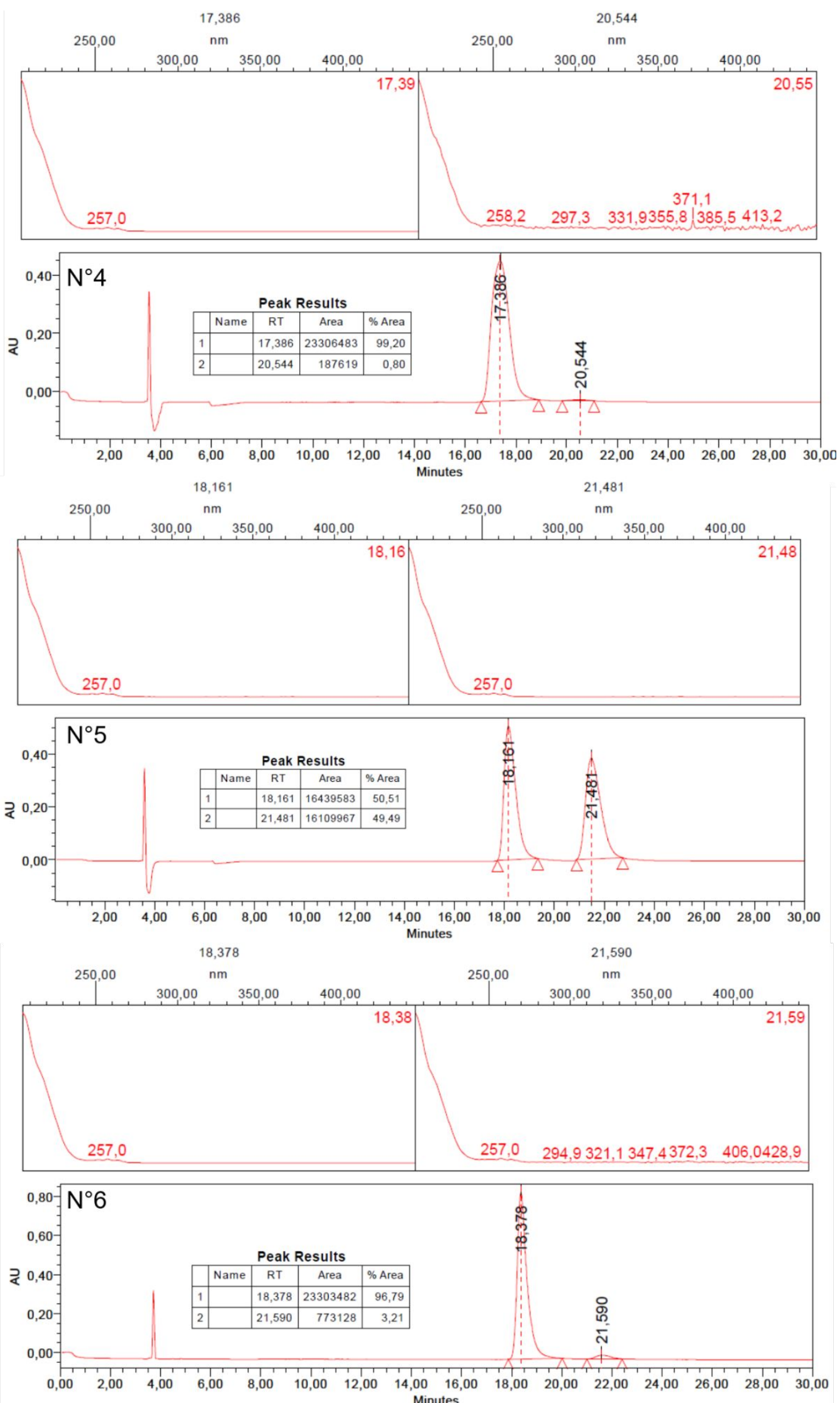

Figure S18. UV spectrum index plot and chiral HPLC chromatograms of the solid outcomes (trial $\mathrm{N}^{\circ} 4$ to $\mathrm{N}^{\circ} 6$ ). The first retention peak is associated to the solvent. The R and S-enantiopurity are given by AUC of the two integrated peaks. 

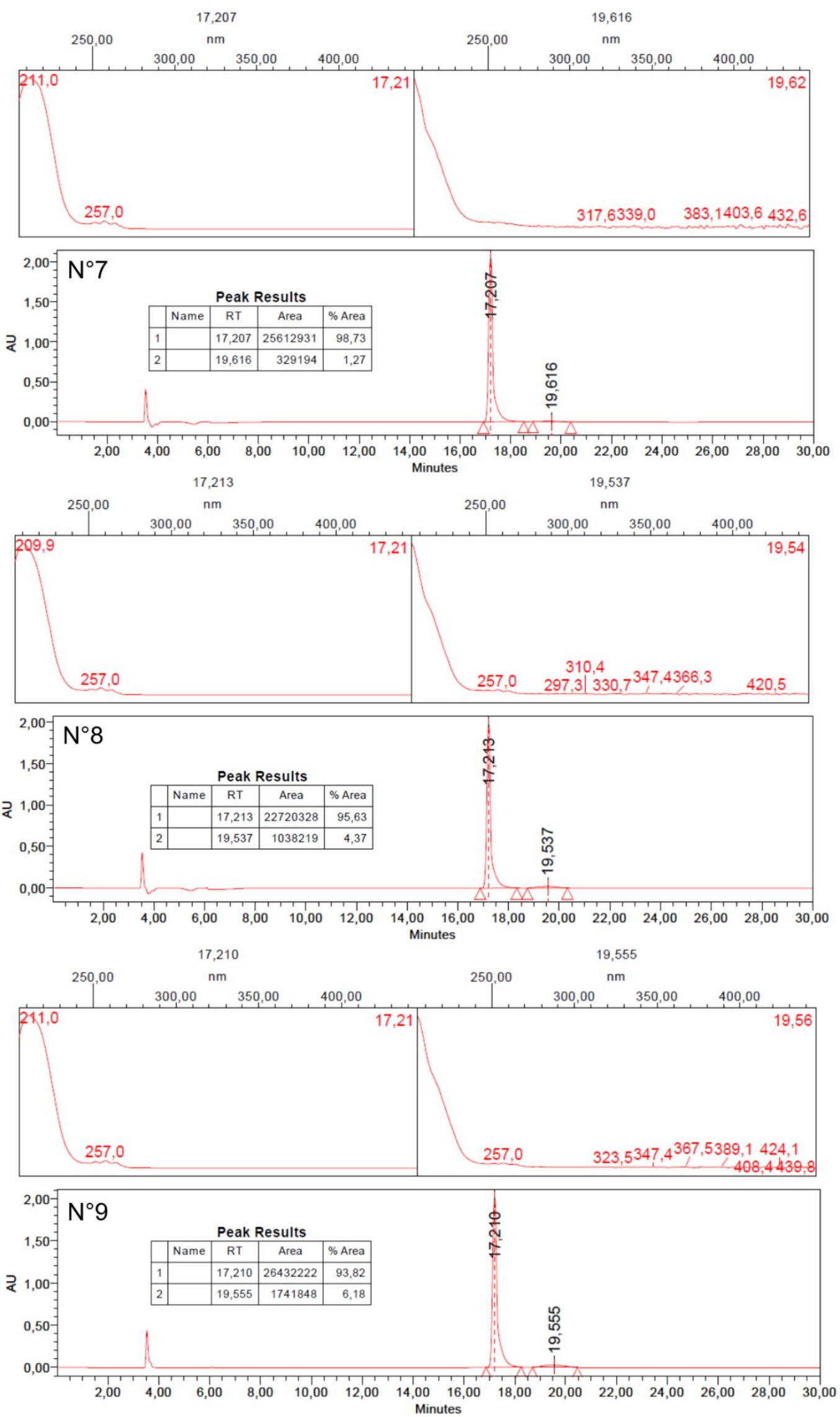

Figure S19. UV spectrum index plot and chiral HPLC chromatograms of the solid outcomes (trial $\mathrm{N}^{\circ} 7$ to $\mathrm{N}^{\circ} 9$ ). The first retention peak is associated to the solvent. The R and S-enantiopurity are given by AUC of the two integrated peaks. 

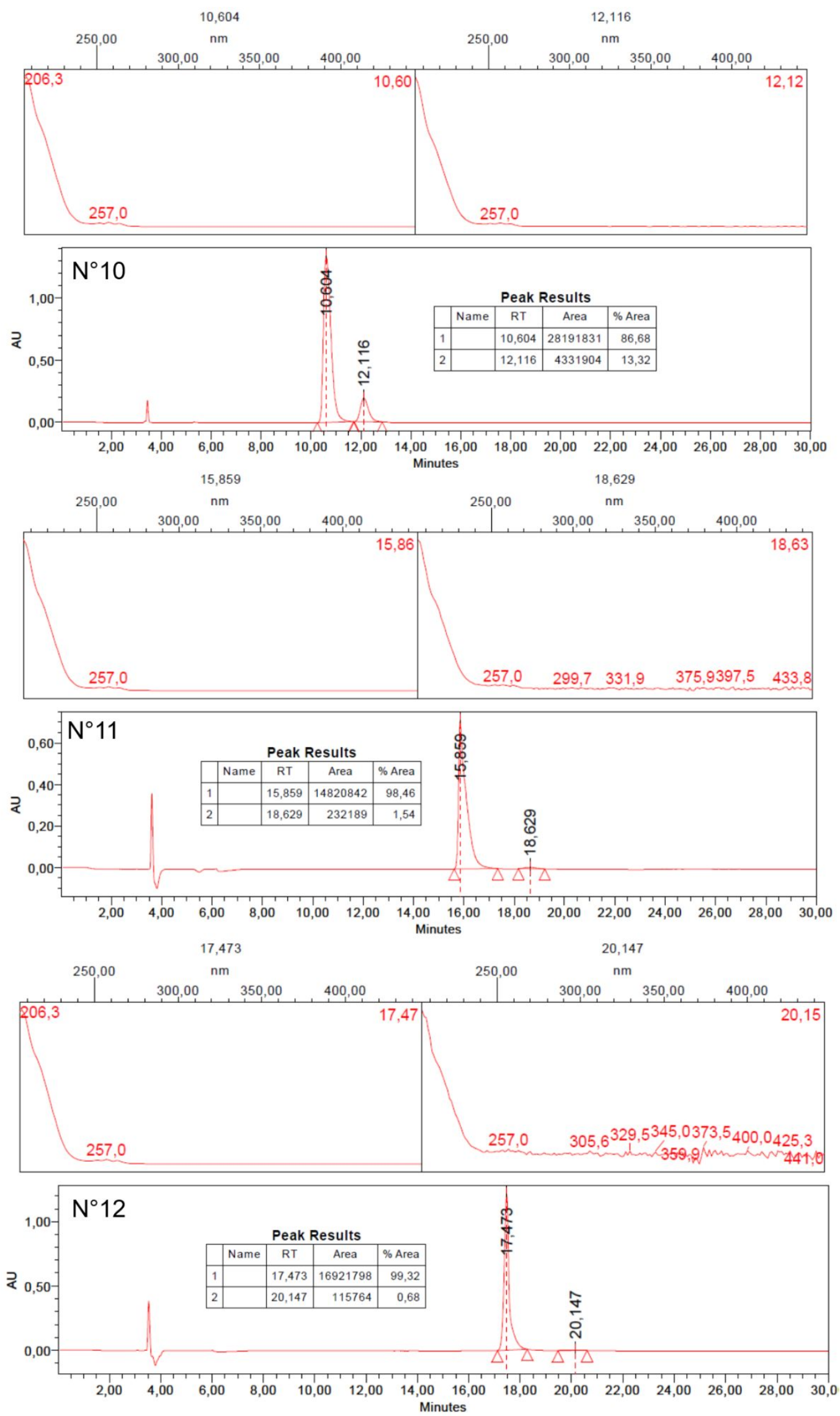

Figure S20. UV spectrum index plot and chiral HPLC chromatograms of the solid outcomes (trial $\mathrm{N}^{\circ} 10$ to $\left.\mathrm{N}^{\circ} 12\right)$. The first retention peak is associated to the solvent. The R and S-enantiopurity are given by AUC of the two integrated peaks. 

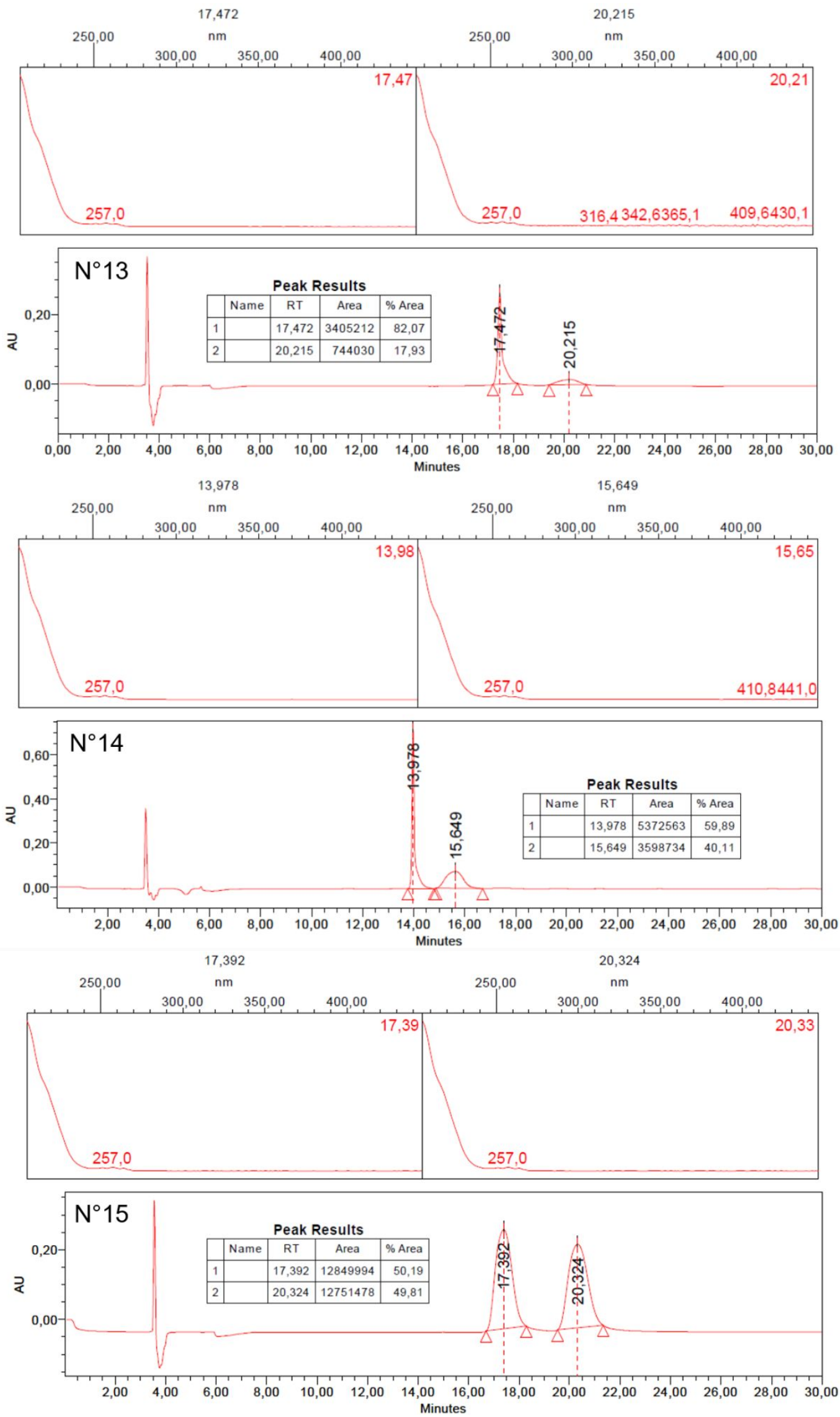

Figure S21. UV spectrum index plot and chiral HPLC chromatograms of the solid outcomes (trial $\mathrm{N}^{\circ} 13$ to $\left.\mathrm{N}^{\circ} 15\right)$. The first retention peak is associated to the solvent. The R and S-enantiopurity are given by AUC of the two integrated peaks. 


\section{Liquid Phase Following-up}
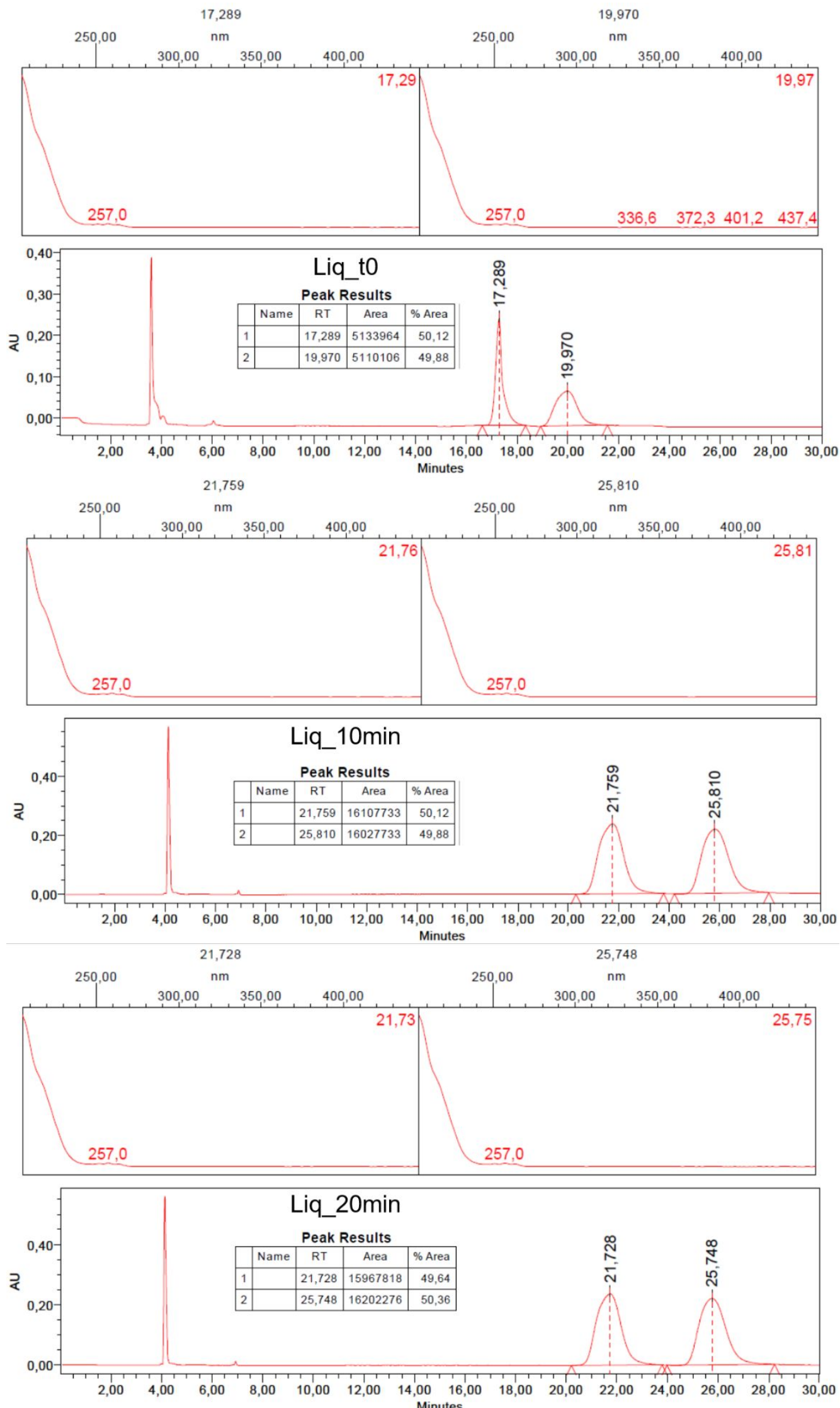

Figure S22. UV spectrum index plot and chiral HPLC chromatograms of the liquid fractions sampled at t=0, 10 and $20 \mathrm{~min}$. 

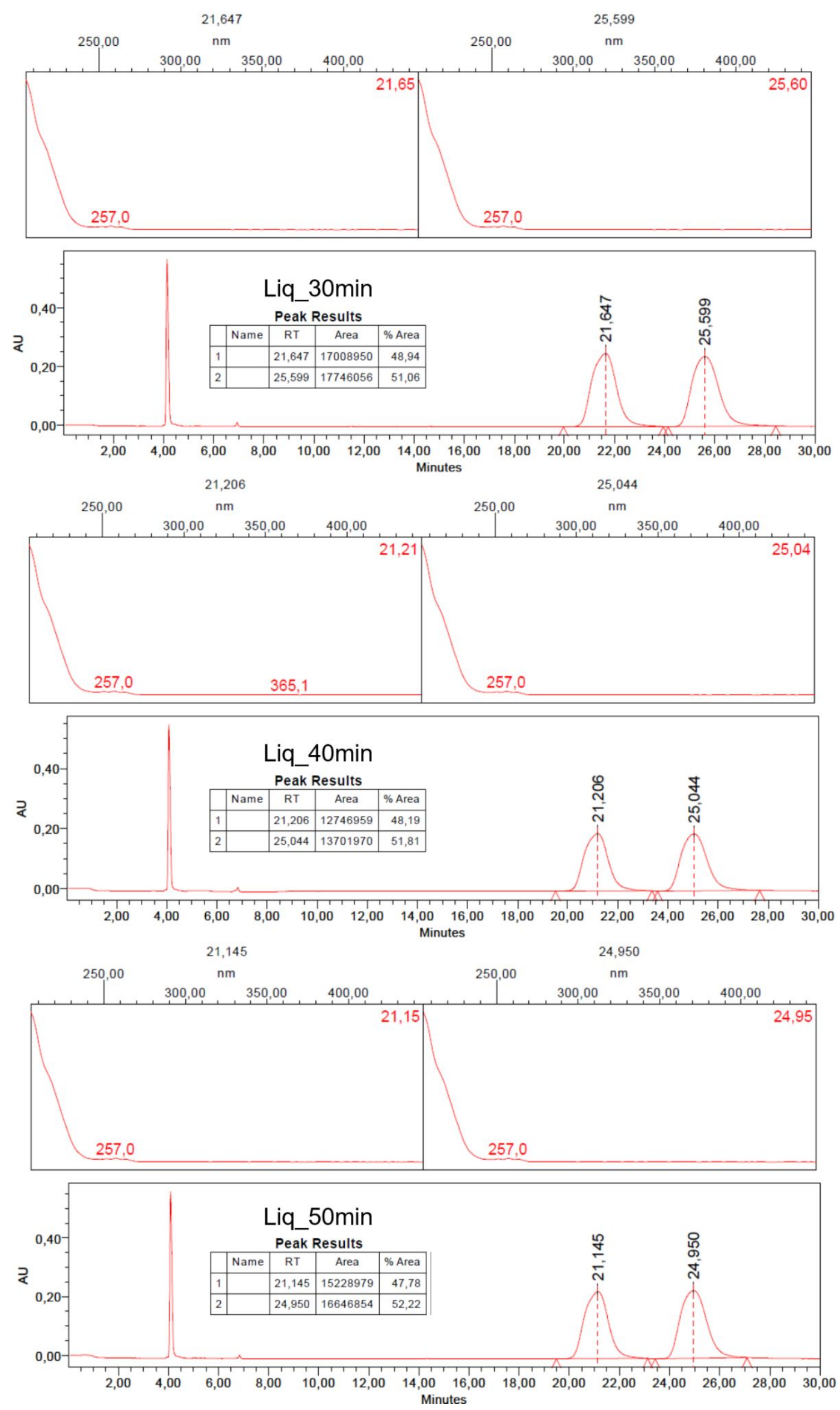

Figure S23. UV spectrum index plot and chiral HPLC chromatograms of the liquid fractions sampled at t $=30,40$ and $50 \mathrm{~min}$. 

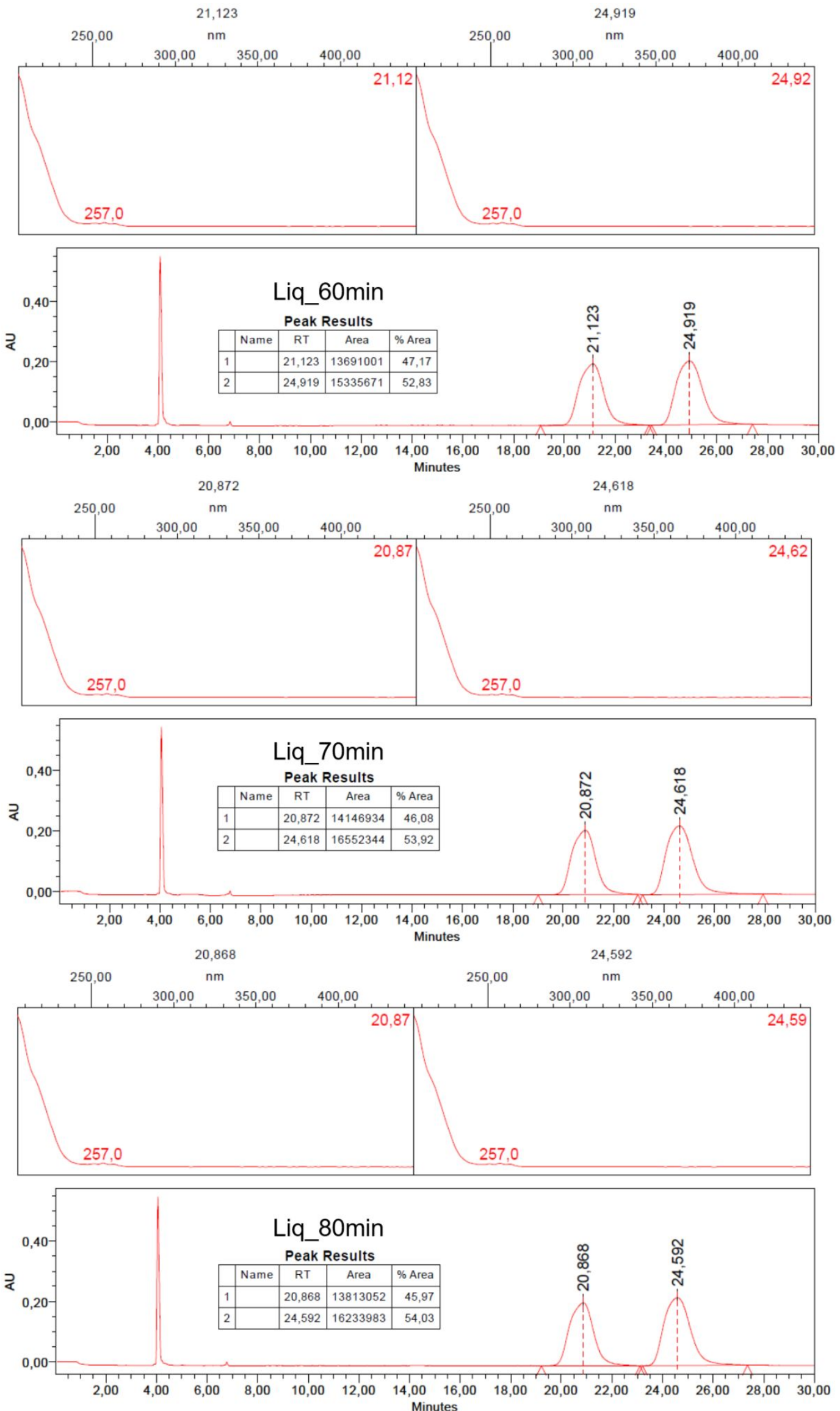

Figure S24. UV spectrum index plot and chiral HPLC chromatograms of the liquid fractions sampled at $\mathrm{t}=60,70$ and $80 \mathrm{~min}$. 

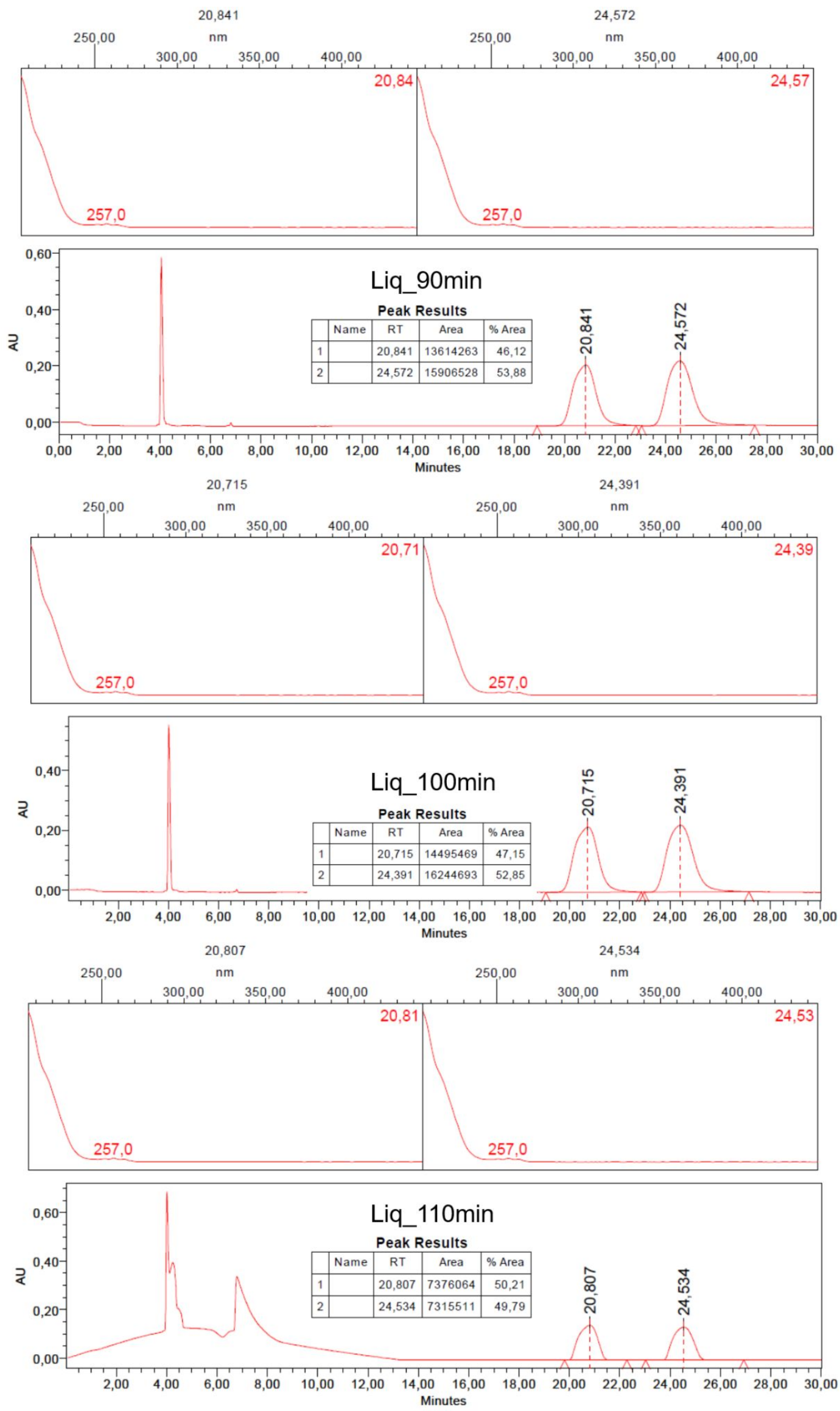

Figure S25. UV spectrum index plot and chiral HPLC chromatograms of the liquid fractions sampled at $\mathrm{t}=90,100$ and 110min. 

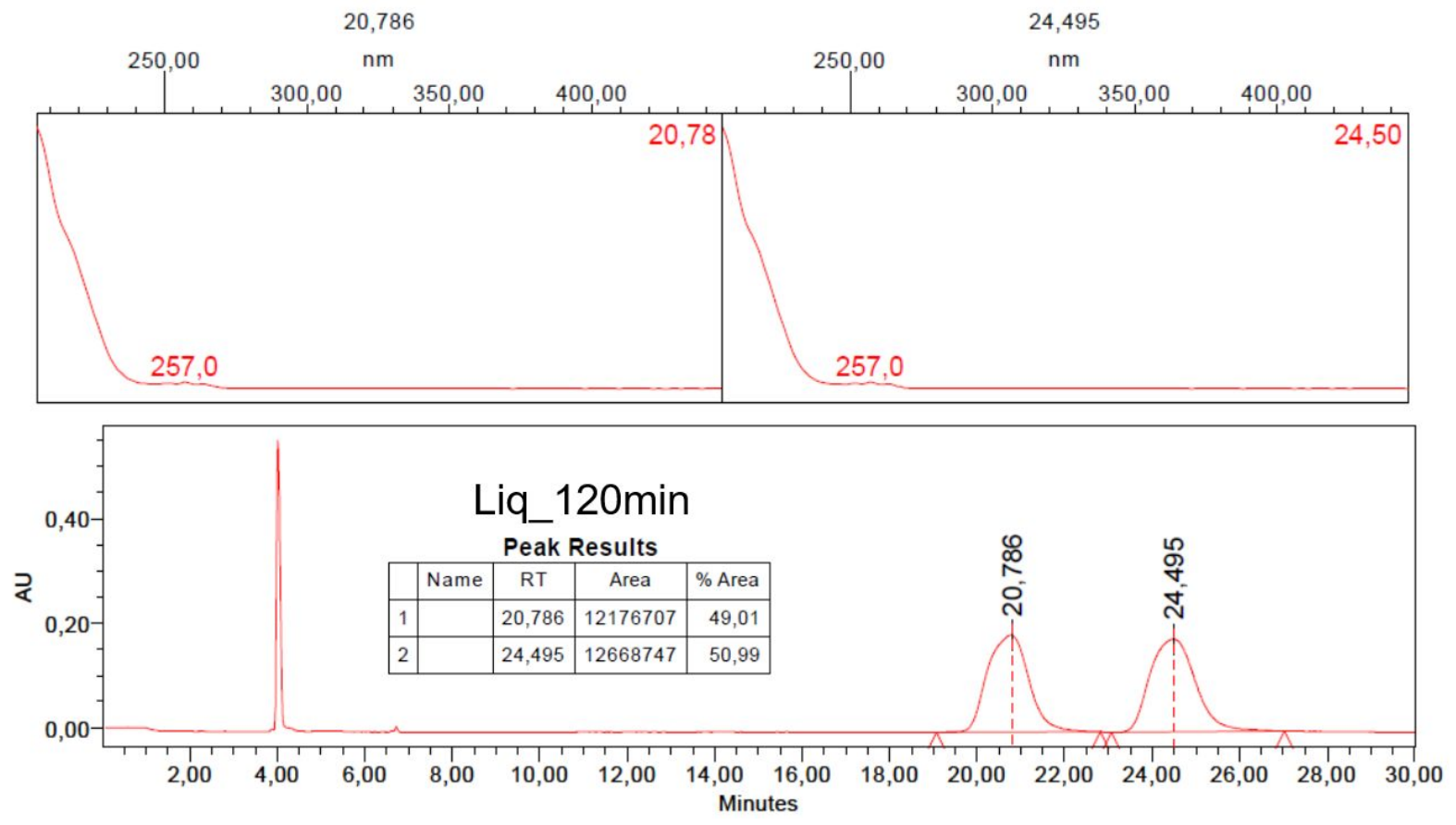

Figure S26. UV spectrum index plot and chiral HPLC chromatograms of the liquid fractions sampled at $\mathrm{t}=120 \mathrm{~min}$. 
Solid Phase Following-up
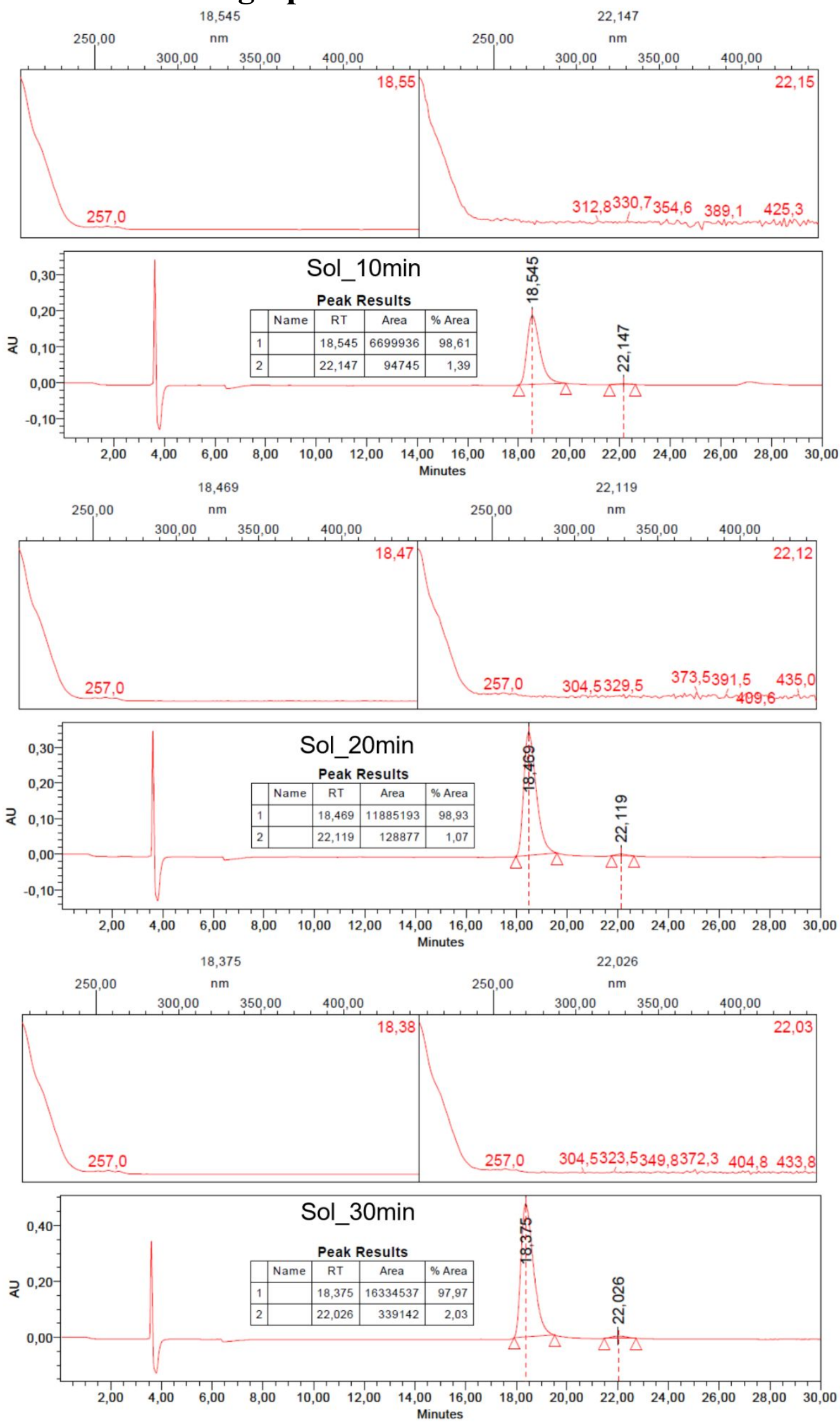

Figure S27. UV spectrum index plot and chiral HPLC chromatograms of the solids sampled at t=10, 20 and $30 \mathrm{~min}$. 

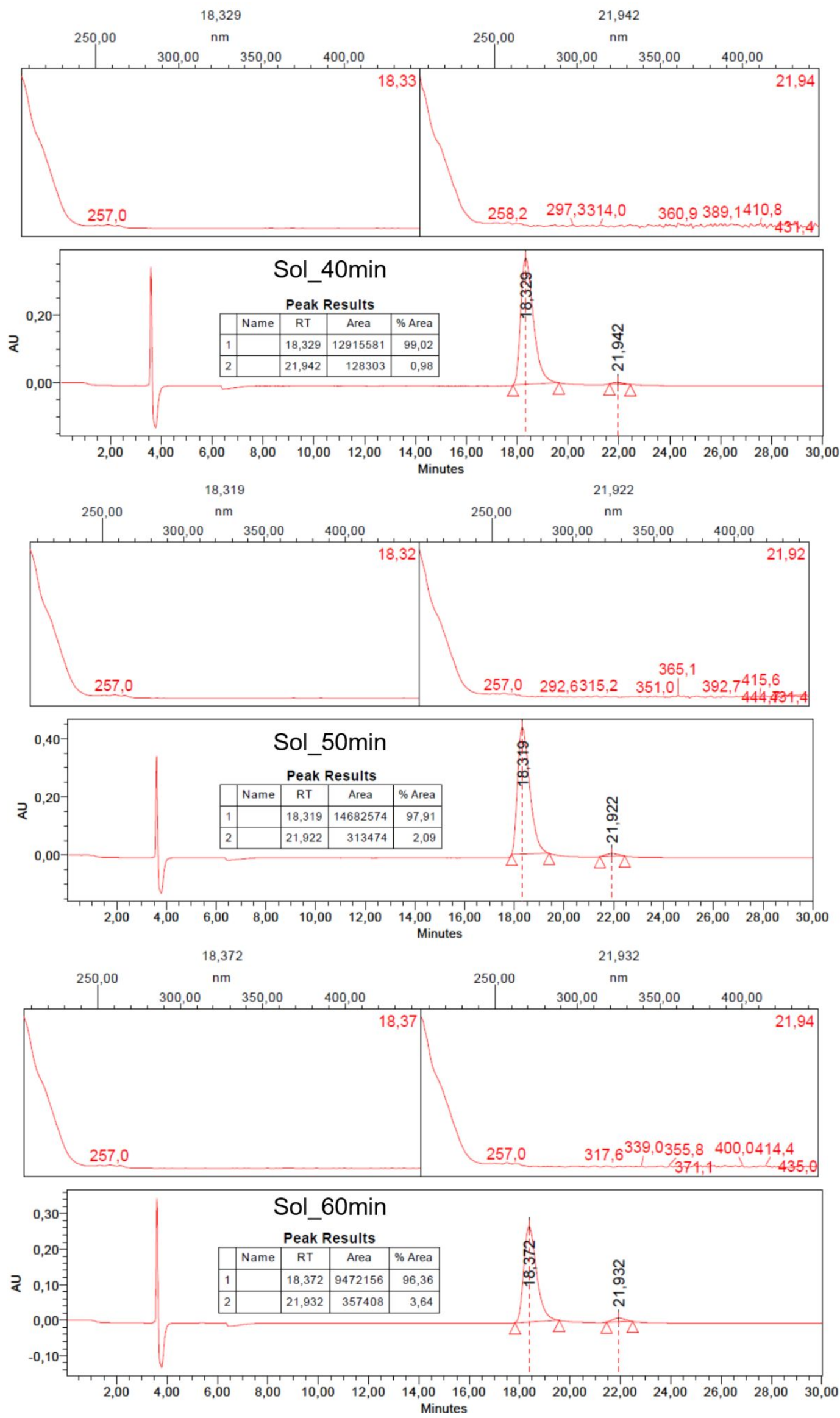

Figure S28. UV spectrum index plot and chiral HPLC chromatograms of the solids sampled at $\mathrm{t}=40,50$ and $60 \mathrm{~min}$. 

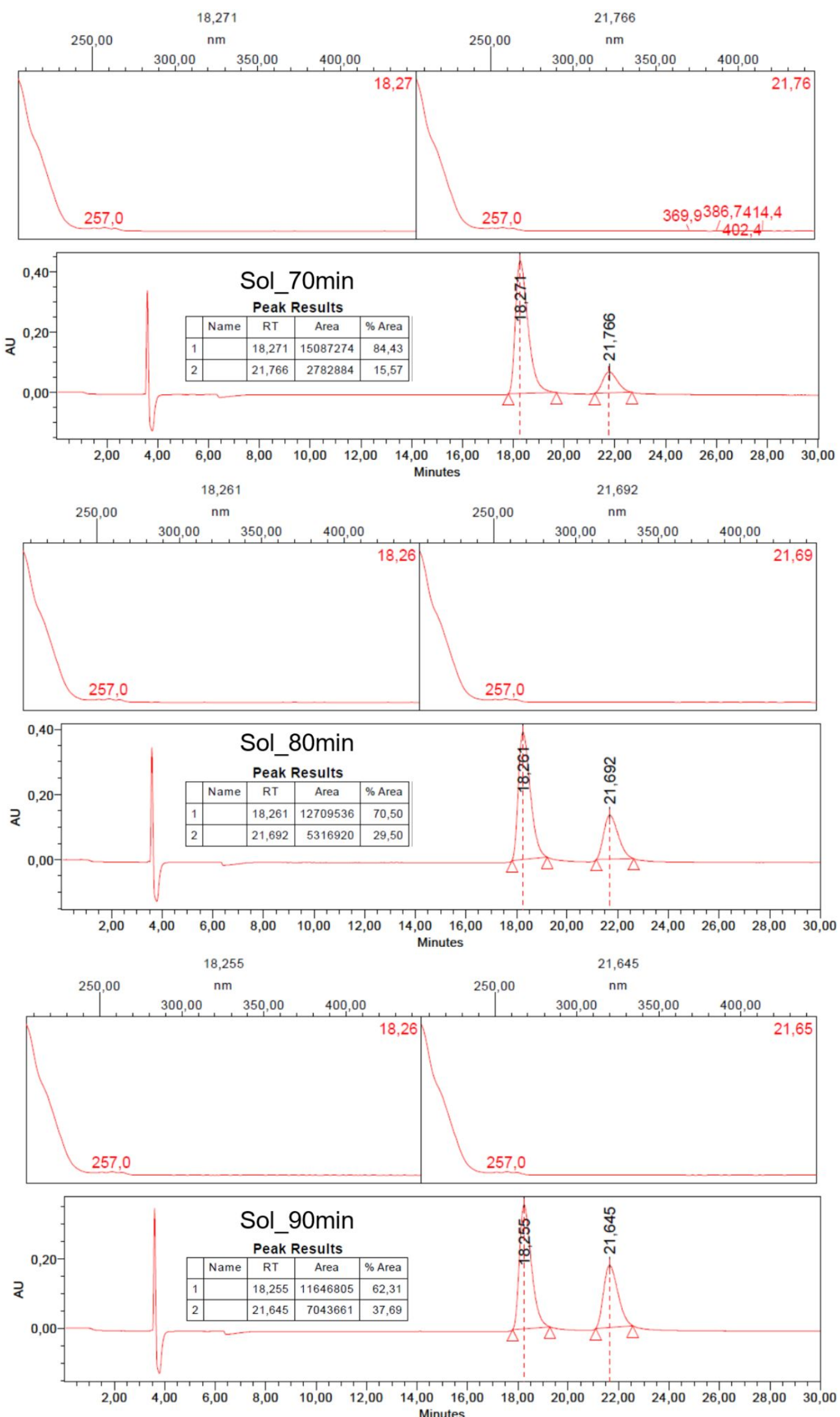

Figure S29. UV spectrum index plot and chiral HPLC chromatograms of the solids sampled at $\mathrm{t}=70,80$ and $90 \mathrm{~min}$. 

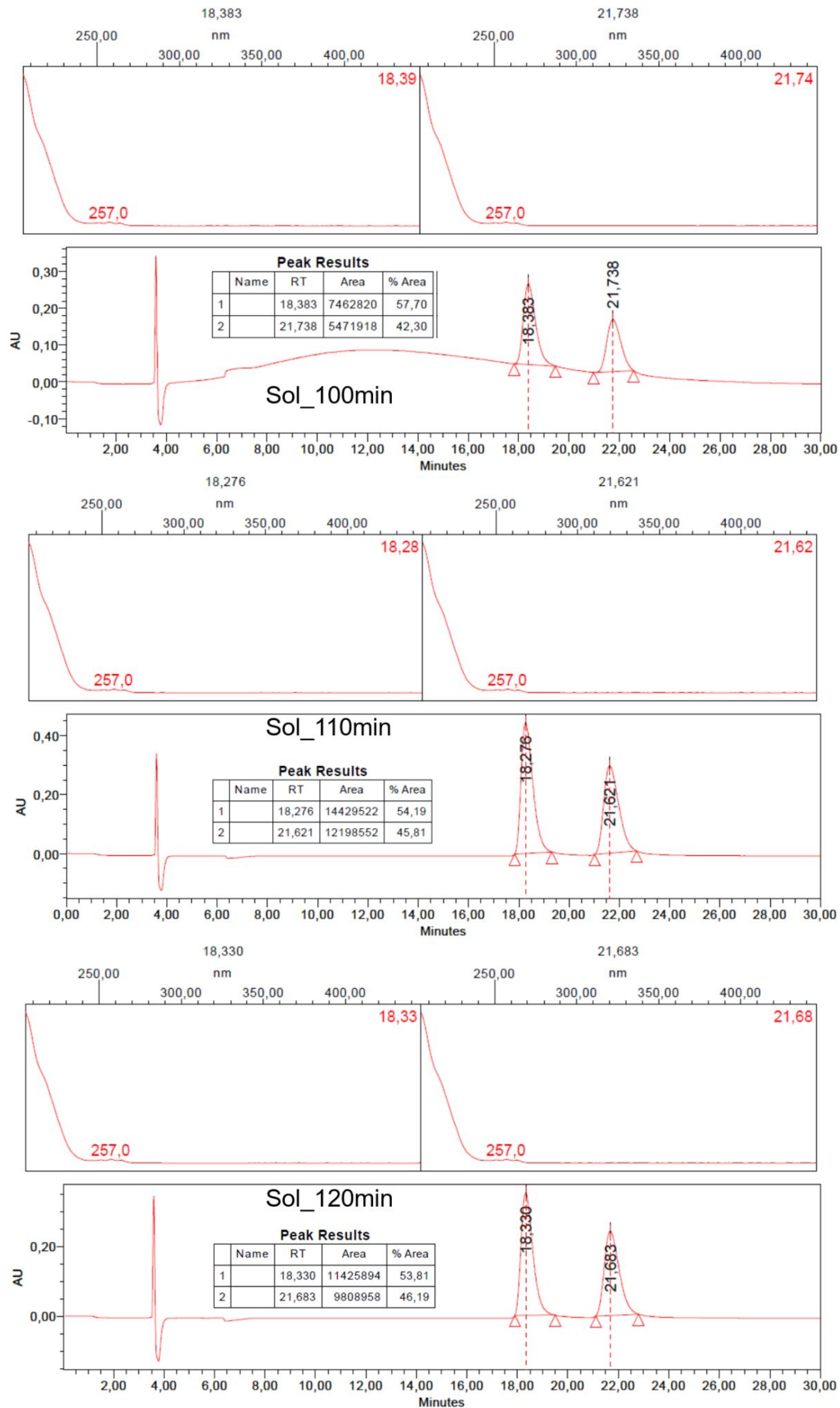

Figure S30. UV spectrum index plot and chiral HPLC chromatograms of the solids sampled at $\mathrm{t}=100,110$ and $120 \mathrm{~min}$. 

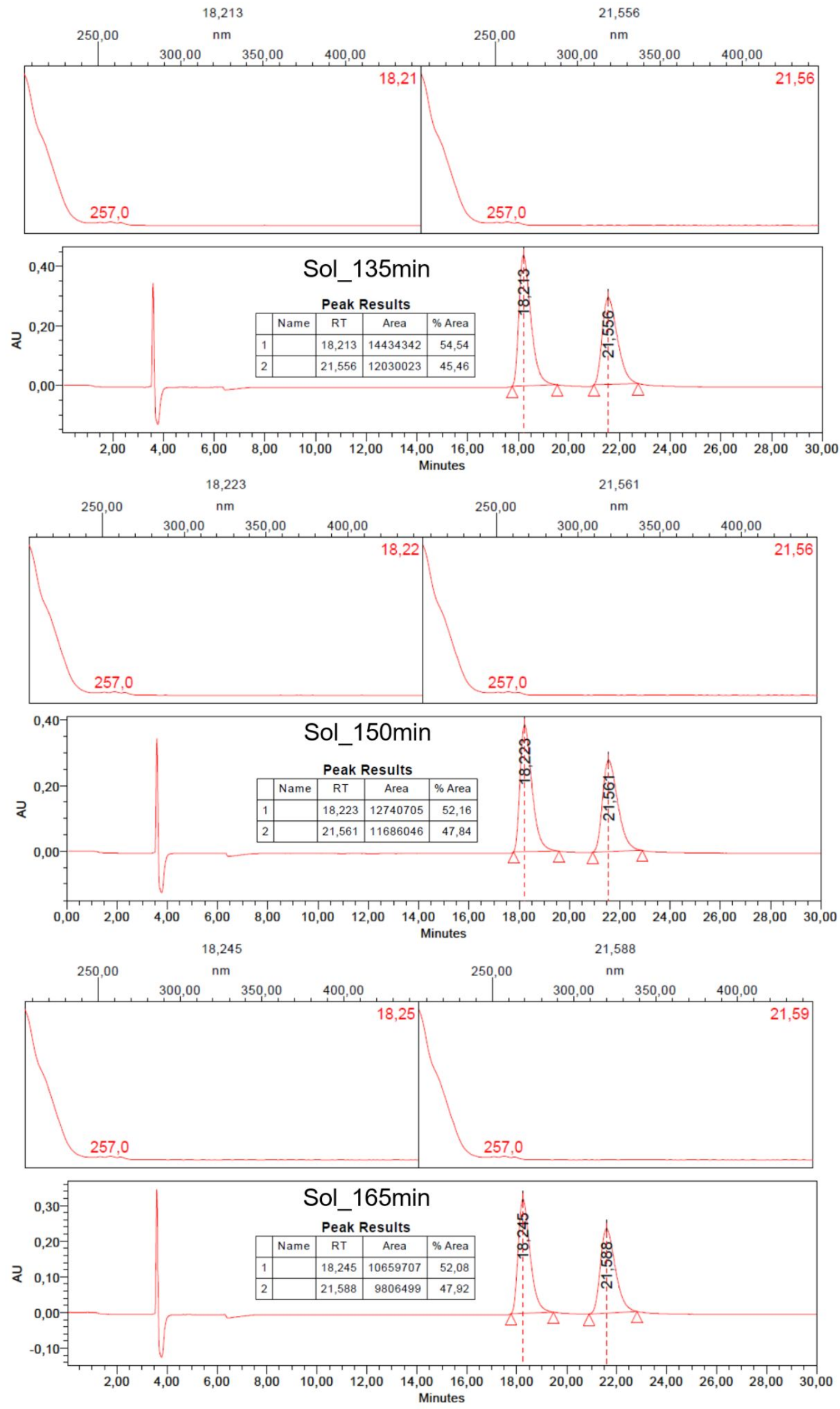

Figure S31. UV spectrum index plot and chiral HPLC chromatograms of the solids sampled at $\mathrm{t}=135,150$ and $165 \mathrm{~min}$. 

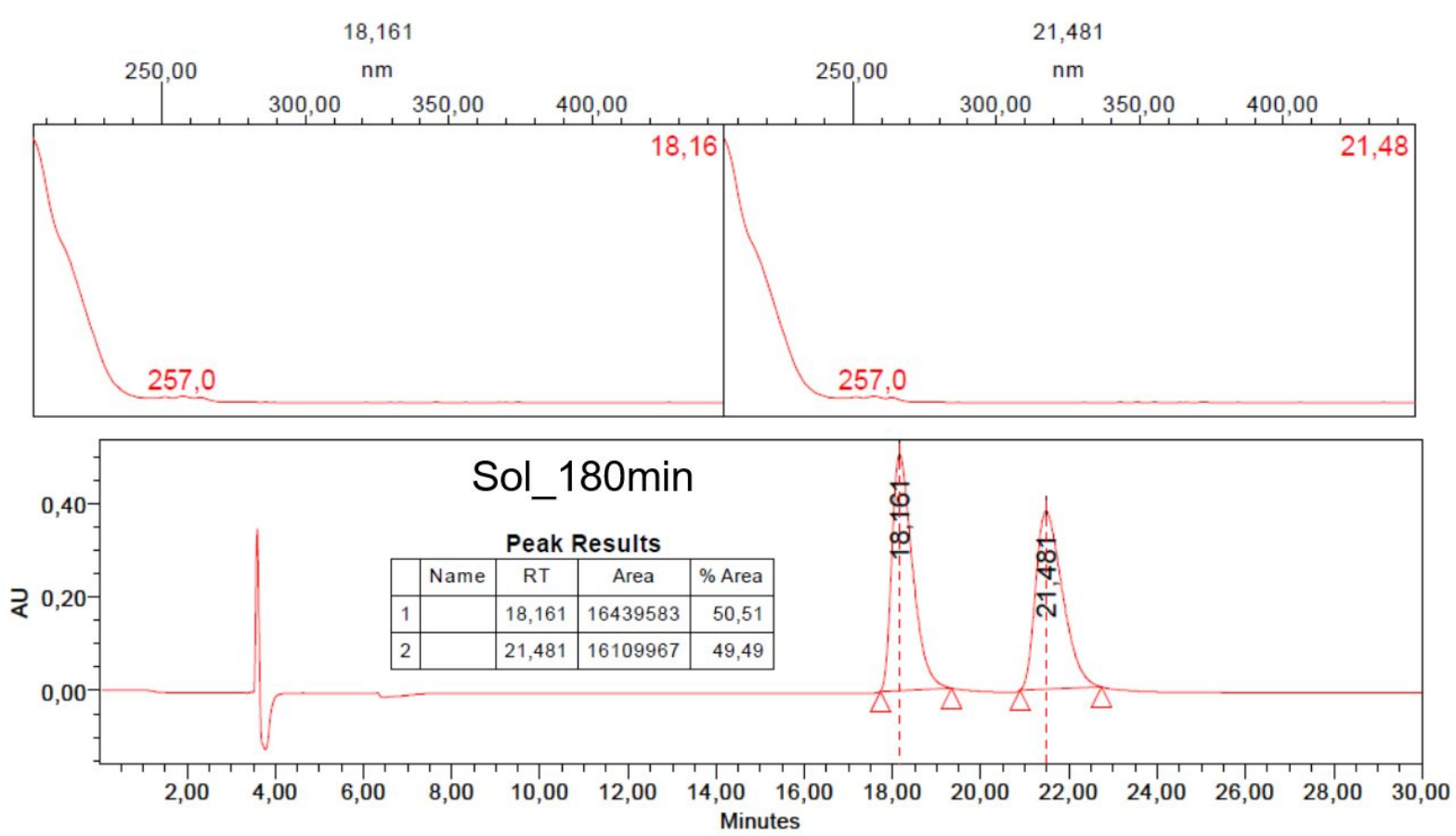

Figure S32. UV spectrum index plot and chiral HPLC chromatograms of the solids sampled at $\mathrm{t}=180 \mathrm{~min}$. 


\section{Continuous Seeded Isothermal Preferential Crystallization}
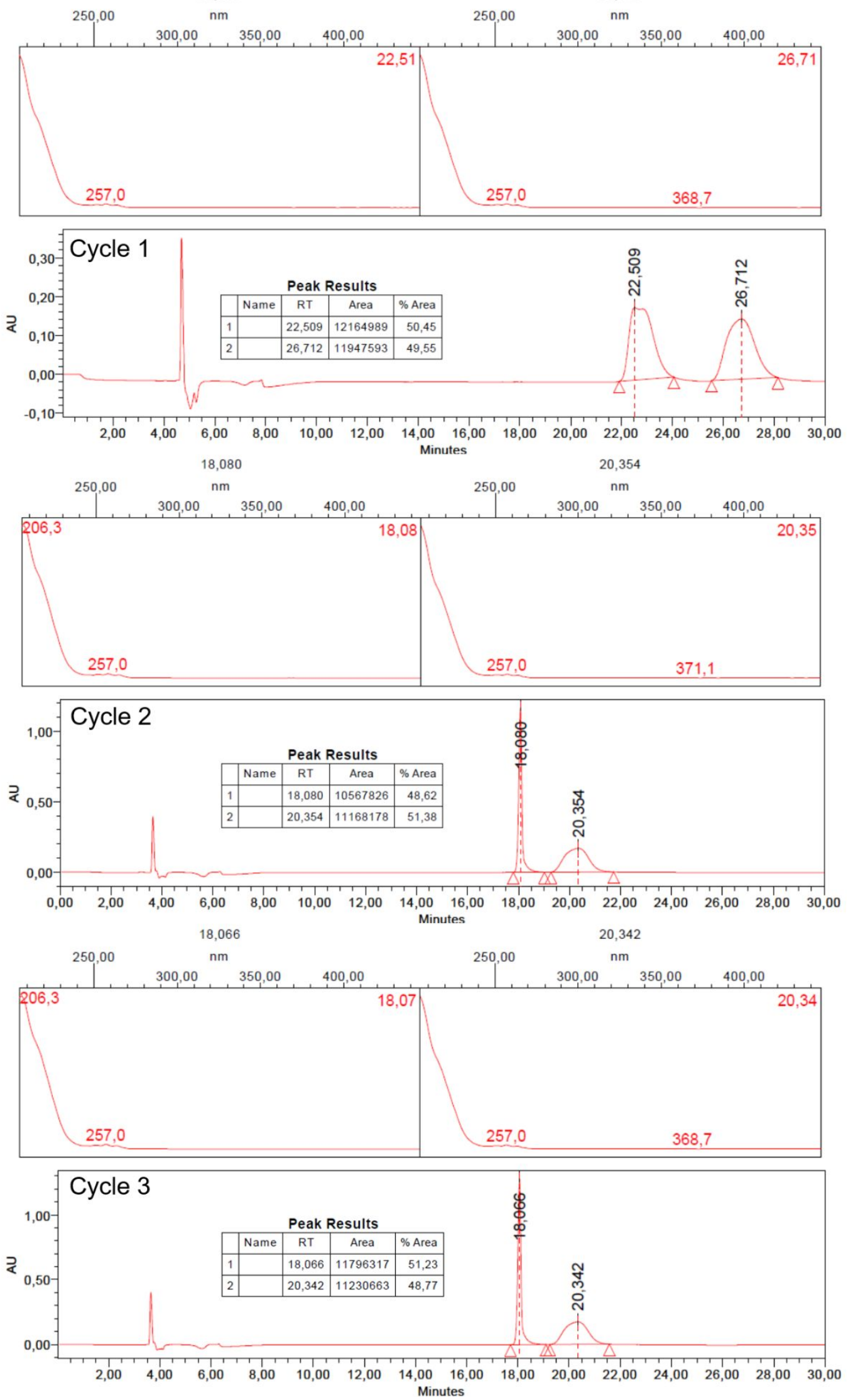

Figure S33. UV spectrum index plot and chiral HPLC chromatograms of the liquid phase (saturation) related to the cycle 1,2 and 3 . 

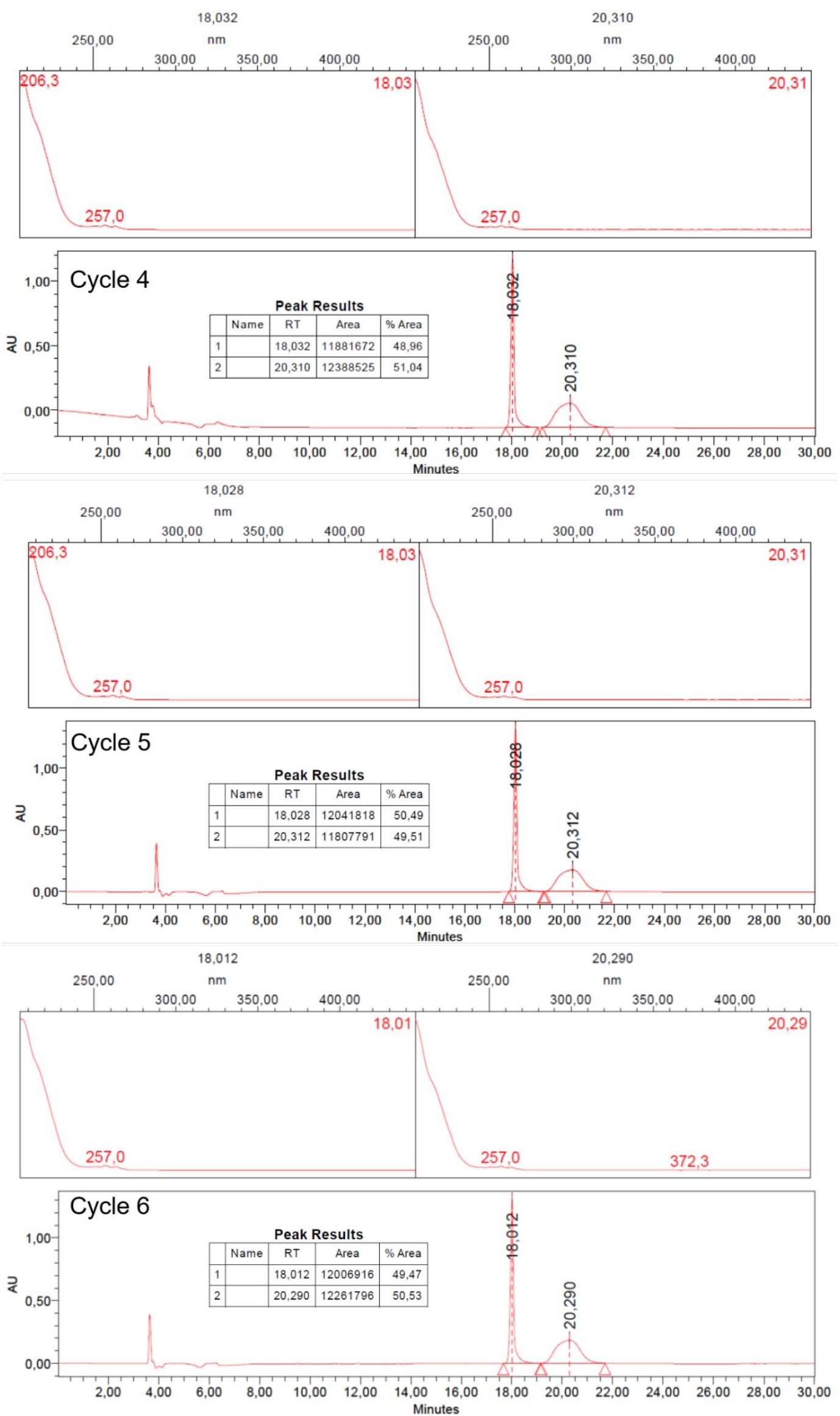

Figure S34. UV spectrum index plot and chiral HPLC chromatograms of the liquid phase (saturation) related to the cycle 4,5 and 6 . 

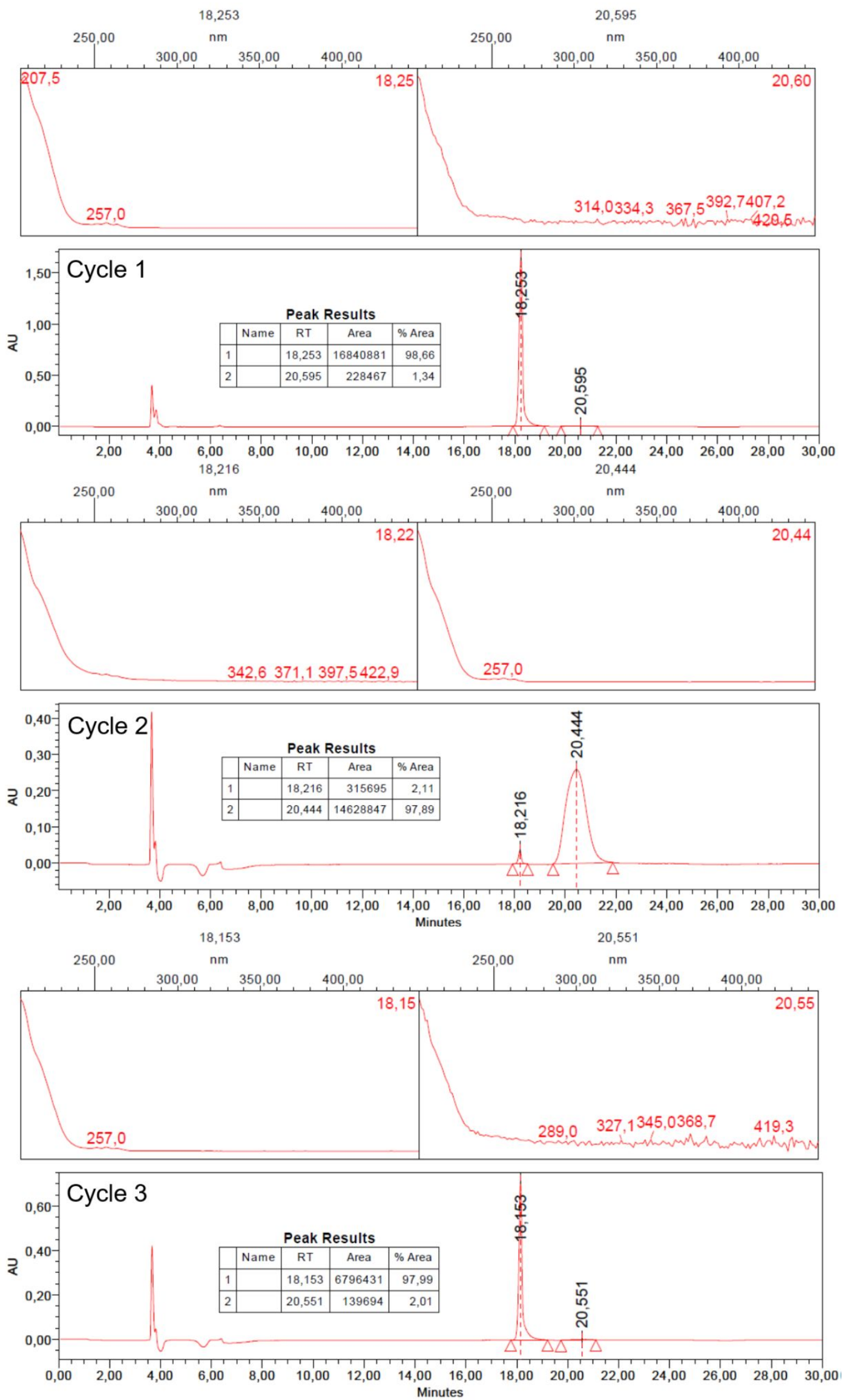

Figure S35. UV spectrum index plot and chiral HPLC chromatograms of the solid outcomes recovered at the end of the cycle 1,2 and 3 . 

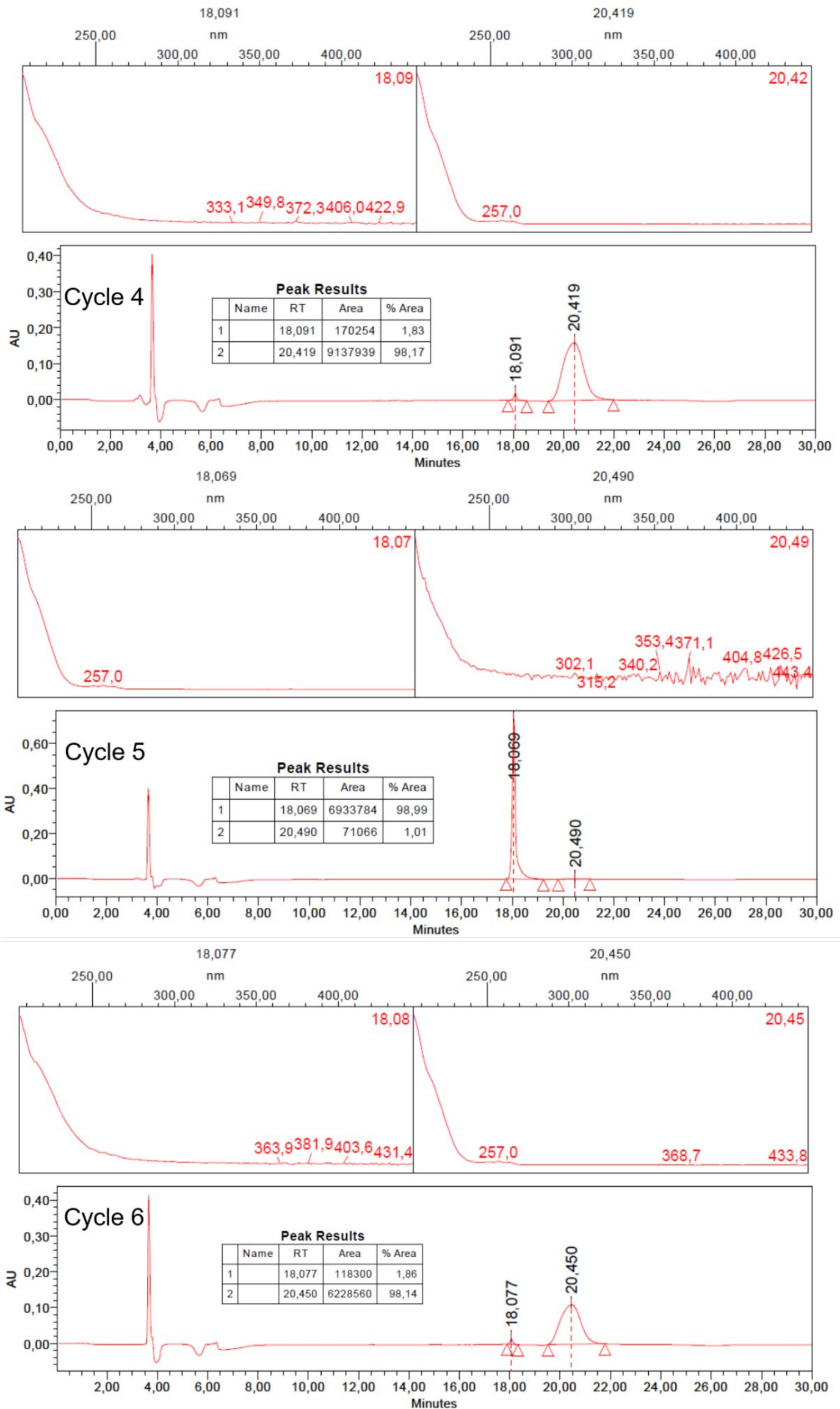

Figure S36. UV spectrum index plot and chiral HPLC chromatograms of the solid outcomes recovered at the end of the cycle 4, 5 and 6 . 


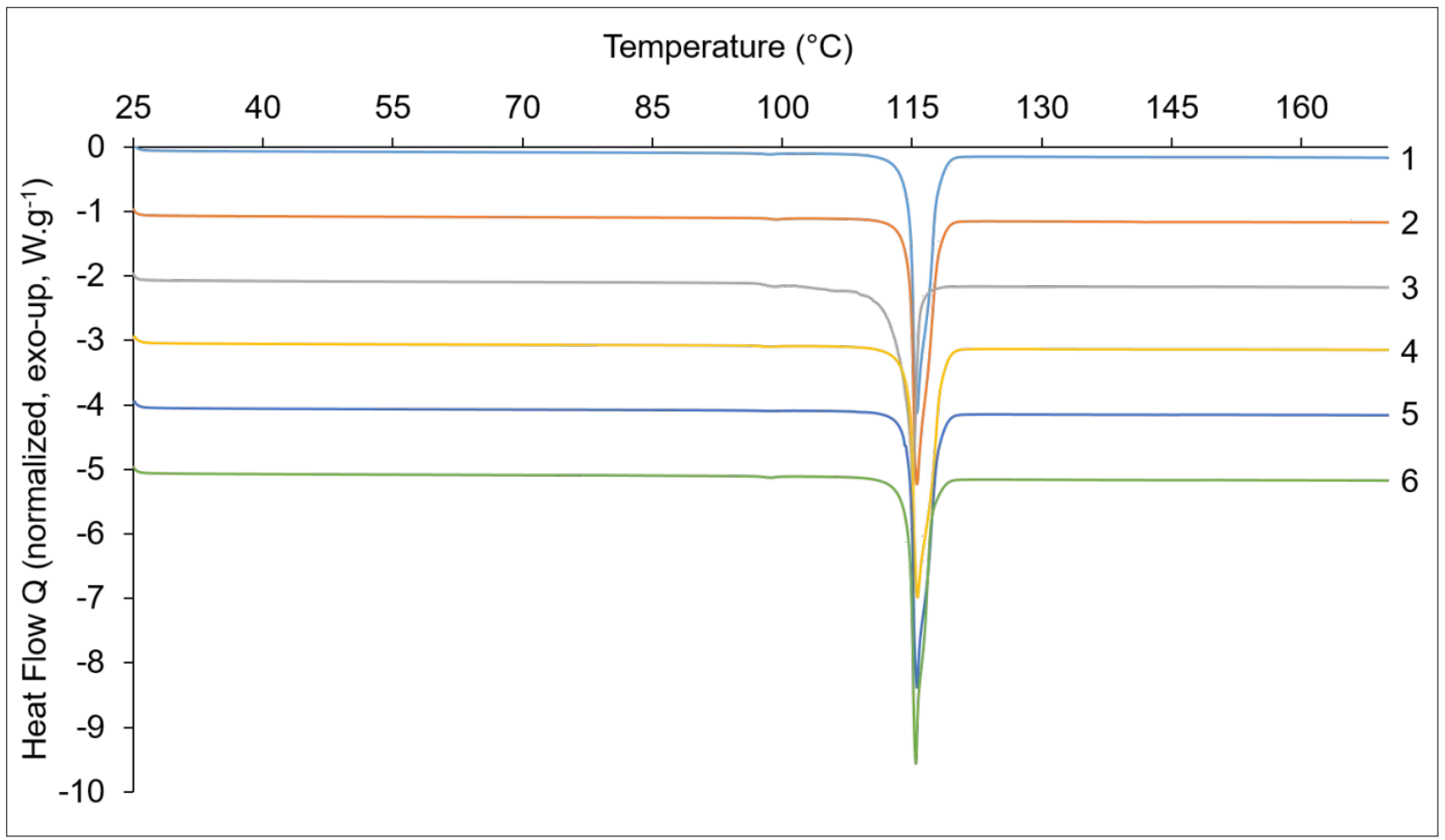

Figure S37. DSC analyses performed on the solid outcomes of the cycles 1 to 6 . 

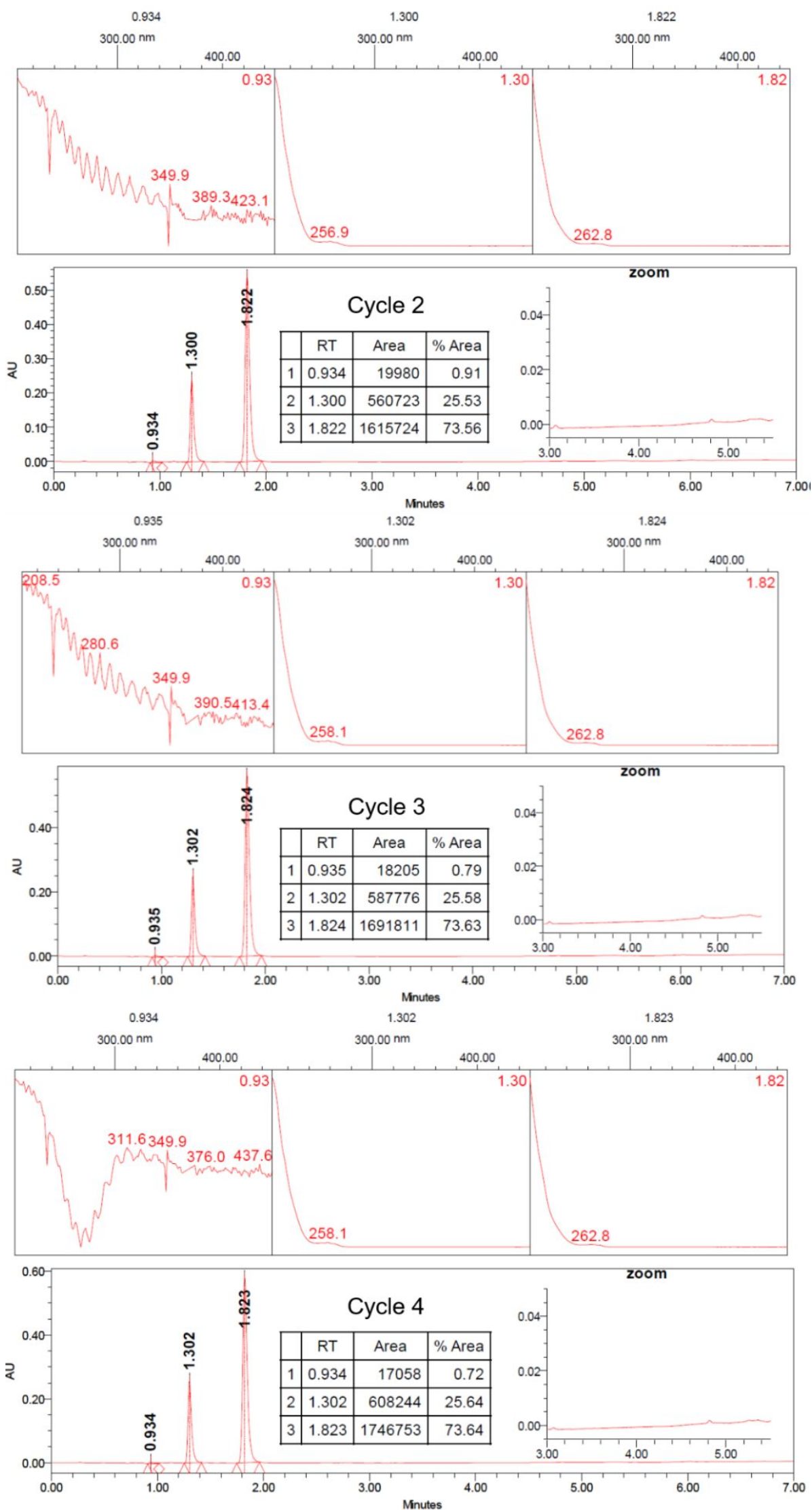

Figure S38. UV spectrum index plot and reverse HPLC chromatograms used to evaluate the NRSMA concentration for the cycles 2 to 4 . The Nefiracetam absorption peak goes out around $1.8 \mathrm{~min}$. 

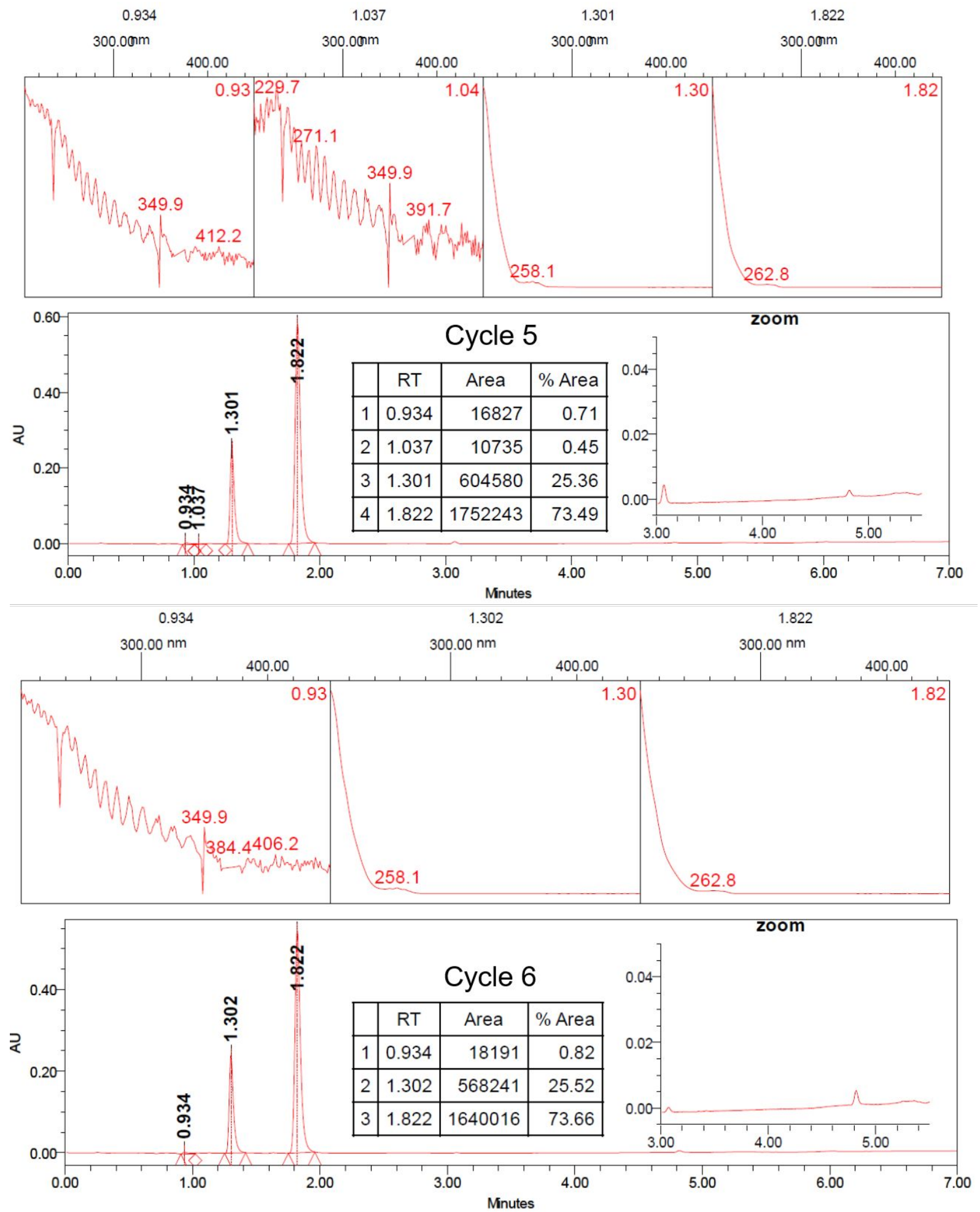

Figure S39. UV spectrum index plot and reverse HPLC chromatograms used to evaluate the NRSMA concentration for the cycles 5 and 6 . The Nefiracetam absorption peak goes out around $1.8 \mathrm{~min}$. 
